\title{
Local Strain Hardening of Metal Components by Means of Martensite Generation
}

\author{
Bernd-Arno Behrens ${ }^{1}$, Sven Hübner ${ }^{1}$, Anas Bouguecha ${ }^{1}$, \\ Julian Knigge ${ }^{1, a}$, Kathrin Voges-Schwieger ${ }^{1, b}$, Katrin Weilandt ${ }^{1, c}$ \\ ${ }^{1}$ Institute of Metal Forming and Metal-Forming Machines (IFUM), \\ Leibniz Universität Hannover (LUH), An der Universität 2, \\ 30823 Garbsen, Germany \\ aknigge@ifum.uni-hannover.de, ${ }^{b}$ voges-schwieger@ifum.uni-hannover.de, \\ cweilandt@ifum.uni-hannover.de
}

Keywords: martensite, material characterization, simulation

\begin{abstract}
The emphasis, in respect of content regarding the here presented project, lies within the production of localized reinforcements, by means of transformation-induced $\alpha$ '-martensite formation in solid and sheet metal components. During the forming process of metastable austenitic steels, high-strength martensite areas, next to ductile austenitic regions, are to be adjusted to enable the production of load-adapted components.

To this end, extensive basic analyses are also necessary in order to determine the description of the mechanical behavior of $\alpha^{\prime}$-martensite structures, as well as to determine the extension of the numerical simulation as regards the structural change.

The results achieved within the area of steel forming include the development of a temperable deep-drawing die $\left(T=-35^{\circ} \mathrm{C}\right.$ until $\left.T=100{ }^{\circ} \mathrm{C}\right)$ that carefully facilitates structural conversion at a constant forming-degree. Moreover the crash performance, based on transformation-induced martensite structures is improved. So-called Forming Curves (FCs) were developed as a new approach towards the material characterization of structured steel.

In bulge forming components, comprised of chrome and nickel steels as well as manganous hard steel, martensite was specifically generated under the use of differing forming parameters. The tool design was aided by Finite Element Analysis (FEA).

Moreover, fundamental simulations were carried out in order to calculate the structural change. The modification and extension of a semi-analytical model of the material followed so that the martensite content could be calculated in the previously examined sheet components, as in the massive forming.
\end{abstract}

\section{Introduction}

During the forming of metastable austenitic steels, transformation-induced martensite can arise. Within the sheet-metal forming, this effect is used to increase the solidity of the formed component. Structure fields were introduced within the process of sheet-metal forming of martensite producing steels via several additional forming-elements. As a result of this structuring, the material was to be additionally stretched on these points to facilitate a change in the component properties. In a crashcase, a defined break, for example in the component, can be achieved by dividing the component in increasingly stretched and non-stretched regions. In order to ascertain the properties of the structure fields in regards to solidity and rigidity, Finite Element Analysis (FEA) simulations, as well as experimental analyses were carried out. By these means, connections could be determined between the properties of the structure fields and the components, their structure, as well as martensite content. Another objective was to make use of the effect of transformation-induced martensite development in metastable and austenitic steels in massive forming as well. More particularly, the possibility was to be created to enable the development of localized strengthened areas in solid components, within the forming procedure. Subsequently, especially strain-adjusted components 
with localized optimated property-profiles such as austenitically, ductile and martensically strengthened areas, are to be produced in the future. To accomplish this, fundamental analyses with the help of different forming processes were carried out, whereby the connections between process parameters and generated martensite were investigated. These analyses were accomplished with the aid of FEA simulation.

\section{The latest research developments}

Within the scope of the projects, a variety of approaches for solutions toward the use of metal transformation-induced phase-conversion of austenite into martensite were analysed. As materials, metastable austenite like EN 1.4318 (X2CrNiN18-7) und EN 1.4301 (X5CrNi18-10) as well as TRIP steels were employed. In the case of metastable austenitic CrNi steels, a transformation of the cubic-surface centralized phase of the austenite can be achieved to some extent as a result of forming at room or low temperatures [20] (Fig. 1). The transformation-induced development of martensite and the associated instance of the flow-tension of metastable austenitic CrNi steel are complex mechanisms that are substantially determined by the parameter alloy-components, temperature, tension and strain conditions.

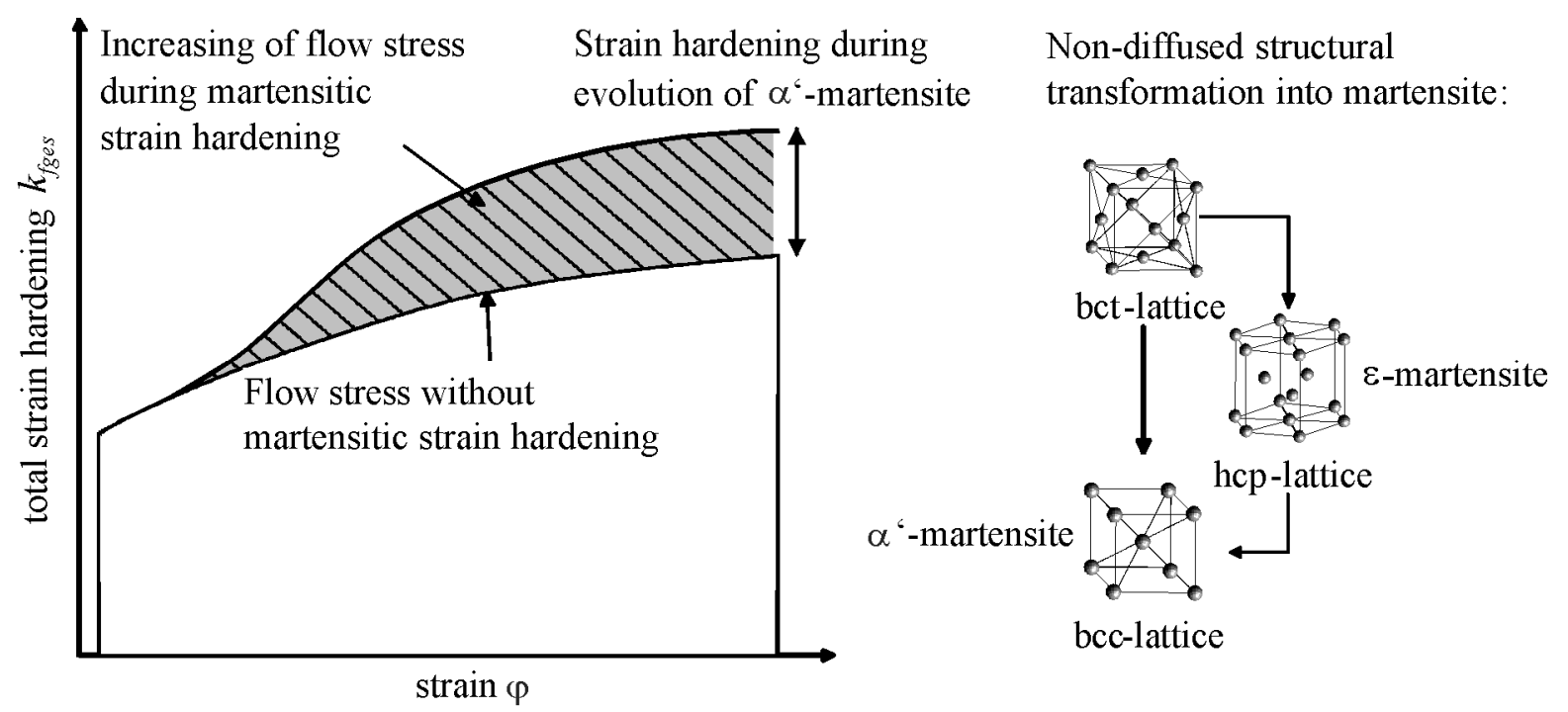

Fig. 1: Reinforcement of metastable austenitic materials [16]

For sheet-metal materials there exist a number of analyses that illustrate the effects of parameters on the martensite development and on the factors of increased strengthening. Several of these analyses shall be presented in the following. Analyses of Angel have already shown that under single-axle tensile load, in the temperature range of $T=-188^{\circ} \mathrm{C}$ until $T=80^{\circ} \mathrm{C}$, the effect of the forming temperature is higher than that of the deep-drawing temperature [1]. Current analyses of Ratte [19] or Talonen [23] have aimed to achieve a description of the $\alpha$-martensite production in stainless steels, especially as regards different temperatures and strain rates. The influence of temperature and expansion behavior on the strengthening properties of TRIP steel was examined with the help of quasi static and dynamic tensile tests for the temperature range $T=-160^{\circ}$ until $T=140{ }^{\circ} \mathrm{C}$ [2]. Lowalloy TRIP steel was tested by means of expansion range dependent tensile-tests to examine the strengthening behavior under temperatures of $T=20^{\circ} \mathrm{C}, T=50^{\circ} \mathrm{C}$ and $T=100{ }^{\circ} \mathrm{C}$ [15]. The result was a maximal strengthening at an expansion of $\varepsilon=0.2 \%$. In order to determine the cause of uneven plastic deformation of TRIP steels, analyses were carried out under consideration of the martensite formation [14]. In CRC 799 of Freiberg's Technical University Bergakademie Freiberg, the production of new TRIP soft solder alloys based on $\mathrm{MgO}$ part-stabilized $\mathrm{ZrO}_{2}$ ceramic and the production of a developed austenitic steel-casting material are currently being studied. The 
emphasis lies on the development, the examination and the extension of the technological processes under the construction of an FE model [17].

The strengthening increase, that develops as a result of the creation of transformation induced $\alpha$ '-martensite, was studied in new projects by means of the correlation between tensile strength, or respectively the limit of elasticity, and the firmness of different materials. In keeping with DIN EN ISO 18265, it is possible to convert hardness values into strength values. At this juncture, a linear correlation of the limits of elasticity, with a hardness of $325 \mathrm{MPa}$ until approximately $1700 \mathrm{MPa}$, as well as of the yield stress in ranges of $450 \mathrm{MPa}$ till $2350 \mathrm{MPa}$ were studied [18]. To that effect, within the scope of the CRC 675 work group in model construction, cross project analyses took place [13].

For bulge forming components, the effect of a transformation-induced martensite development has been little used until now. The effect was restricted to few uses, like bucket-teeth and fork-lift prongs that harden as a consequence of mechanical strain during use. In massive forming, only a few research projects are known. These deal with the occurence of martensite phases through mechanical strain on the components. In current project work, metastable austenite CrMnNi steel casting materials are being analyzed with TRIP effect [21]. The innovation of the metallic matrix rests on the fact that the casting material exhibits high breaking strain of until $70 \%$ at an extremely high strengthening values of over $700 \mathrm{MPa}$, as a result of the TRIP effect. Through a carefully calculated alloying design, these characteristics can be definitively adjusted. Within the sphere of forming technology, foundations for the sinter behavior as well as the forming behavior of particular particle-amplified steel sinter materials are being developed using the TRIP effect.

The effect of functionally close isothermic and thermo-mechanic strain on the forming behavior of metastable austenitic steels was analyzed in [21]. The martensite content in particular, as an indicator for a safe approximate residual life length, was analyzed under operational strain and at functionally relevant temperatures, and integrated in a modeling approach. In the scope of the analyses, the solid forming was examined by the use of compression tests from the forming parameters, to examine the dependence of the martensite content. Furthermore, different forming procedures and component geometrics were analyzed in order to achieve the controlled calculation of the adjustment of martensitic areas in solid components. This took place with the aim of developing locally strengthened areas in components by means of forming.

The parameters of the strengthening mechanisms of martensite formation, as well as for the sheet metal and solid metal forming, have not been sufficiently researched to reach a useful mode of application, despite many examinations.

\section{Methods}

To facilitate the production of strain adjusted components with local properties for highly strong structures, forming processes were selected and developed, with which the transformation-induced martensite formation on metastable austenitic steels can be used with accuracy. To this effect, the ascertainment of the basic connections between process parameters (for example forming velocity, process temperature and forming degree) and martensite formation are necessary.

Based on this, process strategies were developed to purposefully introduce martensitical areas into the austenitic structure of the sheet metal and solid components, so that production steps could be spared during particular processes as a result of actuated and increased strengthening. The analysis of the interactions between the austenitic matrix and during transformation-induced martensitic area proved significant. The results obtained were included in the material modeling and were made useful for process designs thereafter.

The starting point for the projects in the field of sheet steel forming in the first working period was the material characterization of the previously examined materials EN 1.4301, EN 1.4318, EN 1.4372 and TRIP 780 in the tensile test according to DIN EN 10130, as well as the compilation of forming limit curve with Nakajima specimen geometry. Based on this, the introduction of 
structures into the previously examined sheet-metal materials followed with the help of an available deep-drawing die, so that localized $\alpha$ '-martensite strengthening in austenitic ductile regions could be adapted. The martensite content was researched with the help of eddy current based measuring instruments such as the Fischer Feritscope MP3C and the Förster Magnatest D 3.623 and thus validated by means of metallographic analyses. The material behavior of differently structured sheet metals was examined according to DIN EN 10130 and the Nakajima tests. In this case too, the focus lay within an adequate material-specific formulation of the results as regards the international standards of material testing, so that a comparability of results with unstructured sheet metals could be realized. Furthermore, the rolling direction dependency of the phase transformation was studied by means of deep-drawn round-dish geometry, as well as a temperature and frequency analysis in structured experiments. Based on this knowledge, a demonstrator development was carried out in order to examine the crash behavior of structured components. The results obtained created the foundation for the development of a temperated deep-drawing die to carefully and purposefully adjust the local structures in temperature ranges of $T=-30{ }^{\circ} \mathrm{C}$ till $T=100{ }^{\circ} \mathrm{C}$, in order to first use the purposefully directed, controllable $\alpha^{\prime}$-martensite formation and to furthermore strengthen sheetmetal components. To this effect, different punchs, bearing a variety of additional formingelements, were developed with which various forming degrees and hence martensite content was able to be be attained. Because the component geometry is designed to act as a crash demonstrator to a large extent, an additional deformation test-bed was developed at IFUM, for deployment in the hydraulic press Hydrap HDPZb 63, so as to test the structurally influenced folding behavior. The analyses conducted on the deep-drawn components include $\alpha^{\prime}$-martensite measurements, formvarying analyses with the Auto-Grid System from Vialux, micro-hardness measurements as well as parameter studies of the forming temperatures and the structure geometry.

In order to select the appropriate forming processes and punch geometrics so as to introduce the localized additional forming-elements into the metastable austenitic steel X5CrNi18-10, numerical analyses were undertaken by means of the Finite Element Analysis.

The simulation of the forming processes under the variation of the forming procedure and punch geometrics (Fig. 2, left) took place in Abaqus/Explicit. A permeation of the punch into the steel with defined depth was simulated for the replica of the forming processes. The necessary material parameters, like anisotropy co-efficiency and flow curves, derived from various experimental research as well as from the procedure of material characterization. The forming process was illustrated in Abaqus and different variations were calculated, following the analysis of the cap profile of the demonstrator component. The results were compared amongst one another with data from experimental analyses. The tool, by means of which the cap profile is produced, is presented in Fig. 2, right.
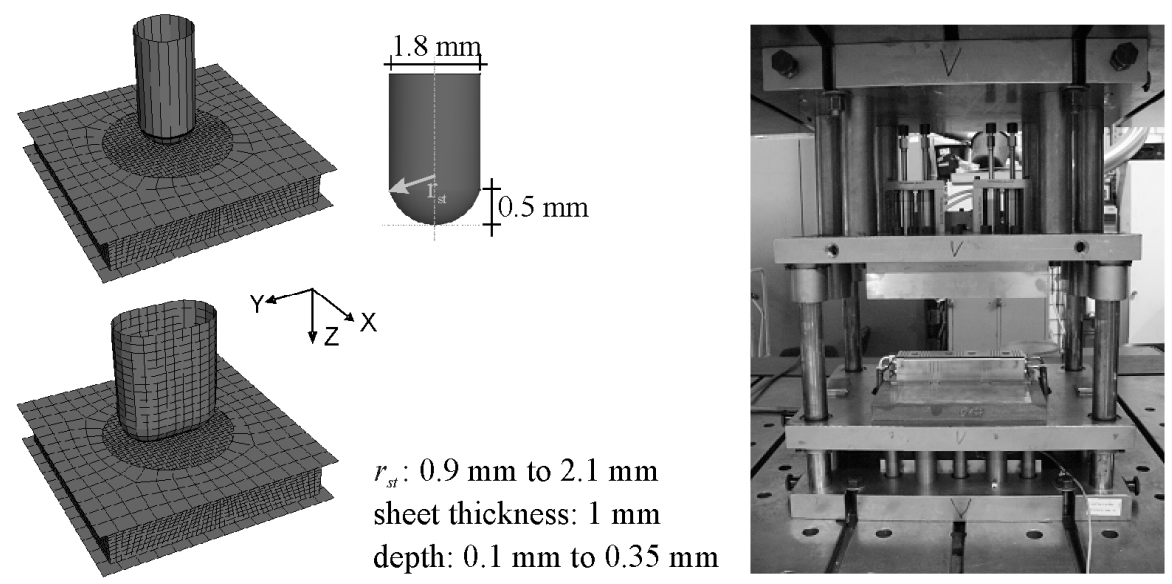

Fig. 2: left: FE-Model for round and oval additional forming-elements

right: Deep-drawing die for defined adjustment of localized martensite content in sheet metal components 
In the course of the projects, the necessity of modifying the existing material model for the numerical description of the martensite formation became apparent. The model, according to [22], has been designated to be used for the simulation of quasi-static tensile strain under the use of shell elements. The extension onto 3D volume elements offers the possibility of analyzing martensite formation in solid components as well as the presentation of the martensite distribution over the test thickness of sheet metal components.

The basic analyses of martensitic phase conversion in solid, metastable, austenitic stainlesssteels, occurred on account of upsetting tests with which the dependence of the martensite content on the true strain, the strain rate, the temperature of the work-piece, and on the material was examined. Based on these analyses, backward cup extrusion (BCE) tests followed, in which, next to the above mentioned parameters, additionally the variation of the tool temperature took place. Finally, a combined hot-forming and cold-forming process was actualized. Within this, a pre-form was first of all produced through hot-forming. During the final cold-forming process, the adjustment of the martensite content was realized.

Within the scope of the first examinations, five different materials were selected and structural research was carried out (1.4301 [X5CrNi18-10], 1.4404 [X2CrNiMo17-12-3], 1.4542 [X5CrNiCuNb16-4], 1.4571 [X6CrNiMoTi17-12-2], 1.3401 [X100Mn12]). The raw material bore partly large quantities of martensitic phase content.

In order to use a homogenous, martensite-poor structure for the forming tests, the temperature was determined for all materials in which recrystalization sets in, within dilatometer experiments. Above this temperature, which is marked in the iron-carbon-diagram through the GS line (A3 line), the material converts into $\gamma$-mixed crystals. Parts of the upsetting specimens were subjected to heat treatment above the researched, material-specific recrystalizations temperature before the forming process.

Upsetting tests with a servo-hydraulic plastometer were carried out in order to ascertain the basic connections between the process parameters within the forming process and the martensitic structure in which this results in. The plastometer used possesses a maximal force of $400 \mathrm{kN}$ and is meant to receive flow curves. The velocity of the ram is adjustable from the quasi-static upsetting test until $2.2 \mathrm{~m} / \mathrm{s}$.

The specimens, with a diameter of $11 \mathrm{~mm}$ and a height of $18 \mathrm{~mm}$, are to be placed between upsetting tools within a thermal container (Fig. 3). Next to the parallel guiding of the tools, the thermal container prevents either the cooling or heating of the specimens and the tools, during the experiment process. The friction residing on the contact area between the tools and the specimen is reduced by means of Teflon foil. This enables the upsetting tests to take place under constant conditions, above and below room temperature. Next to the temperature, the true strain and the strain rate can be varied according to any material. End-stop rings with various heights that are additionally placed in thermal container to realize an exact repetition of the true strain.

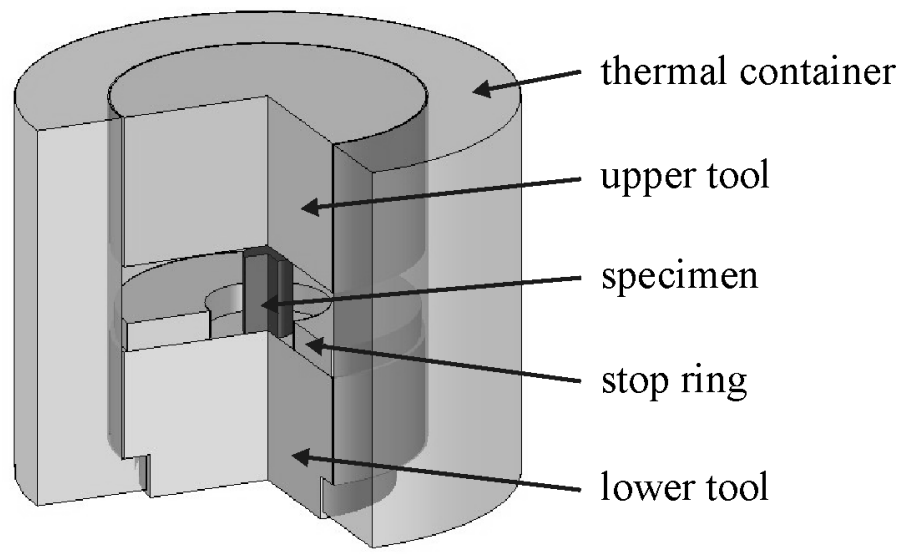

Fig. 3: Specimen for upsetting test with back-stop ring in the thermal container 
The parameters for the upsetting tests are presented in Table 1. Each material was analyzed according to a selected set of these parameters. In Fig. 4, a row of experiments are presented, in which the forming degree is varied.

Table 1

\begin{tabular}{|l|l|l|}
\hline Strain rate & $\dot{\varphi}[1 / \mathrm{s}]$ & 0,$1 ; 1$ and 20 \\
\hline True strain & $\varphi[-]$ & 0,$05 ; 0,1 ; 0,2 ; 0,3 ; 0,5 ; 0,8$ and 1 \\
\hline Temperature & $T\left[{ }^{\circ} \mathrm{C}\right]$ & $-5 ; 20 ; 60$ and $100{ }^{\circ} \mathrm{C}$ \\
\hline
\end{tabular}

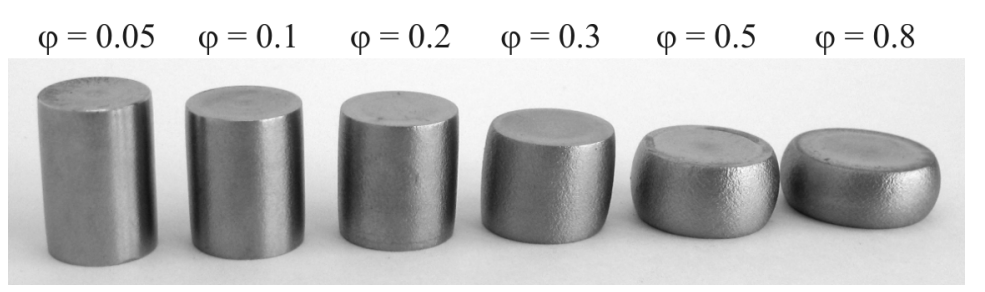

Fig. 4: Stepwise experiments during the upsetting test in order to analyse the martensite content, depending on the forming degree

In order to analyze the martensite concentration and distribution and to achieve a better comprehension of the procedures taking place during the forming process, magnetic field measurements with the use of the Feritscope as well as metallographic analyses were carried out. The flow curves and the analyzed martensite concentration depending on forming parameters form the basis for the following examinations and are used as input parameters for FEA simulations.

Numerical analyses were undertaken in concordance to the local strengthening of massive forming components. The analysis of the upsetting procedures, are based on the existing material model under the exertion of the rotation symmetry in Abaqus. Finite Element Analysis in the software Forge, supported to the set up and construction of the necessary tools.

For the investigation of local strengthening in massive forming components out of the material EN 1.4301 (X5CrNi18-10), the backward cup extrusion (BCE) was examined. To accomplish the experiments, a hydraulic press of the firm Schirmer and Plate, bearing a nominal force of $12500 \mathrm{kN}$, was modernized with financial help from the DFG. For the forging tests a modular constructed hot and cold forming tool (Fig. 5), adjusted to the press, was developed. In order to produce different component geometrics, the implementation of different die sets is possible. In addition to this, the tools could be heated up to $T=300{ }^{\circ} \mathrm{C}$. A tool guiding frame, equipped with a load cell, was used in order to guide the upper and lower tools. The adapters between tool and die-set were fitted with a thermal isolation in order to facilitate a hot forming and to consequently allow to minimize the heat transition from the tool into the press. 


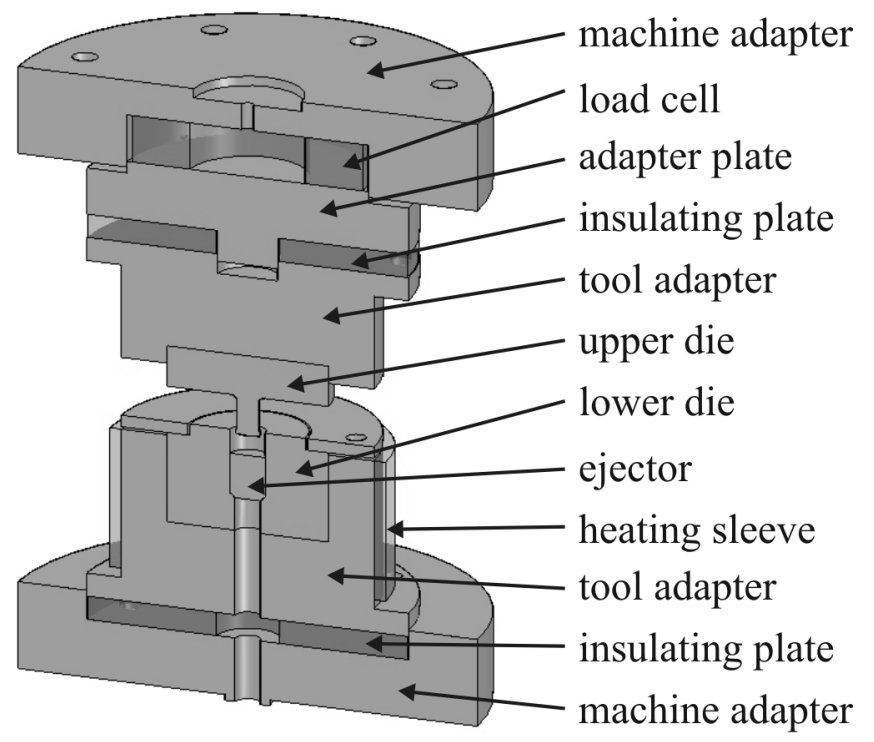

Fig. 5: Modular hot and cold forging tool

The BCE was selected for the experiments within the scope of this project because tensile, as well as pressure stresses, arise during the forming process. The principle of the BCE is shown in Fig. 6. As a consequence, depending on the stress state, different structural states can be adjusted in a massive forming component. Particularly tensile stresses are supposed to promote the formation of martensite.

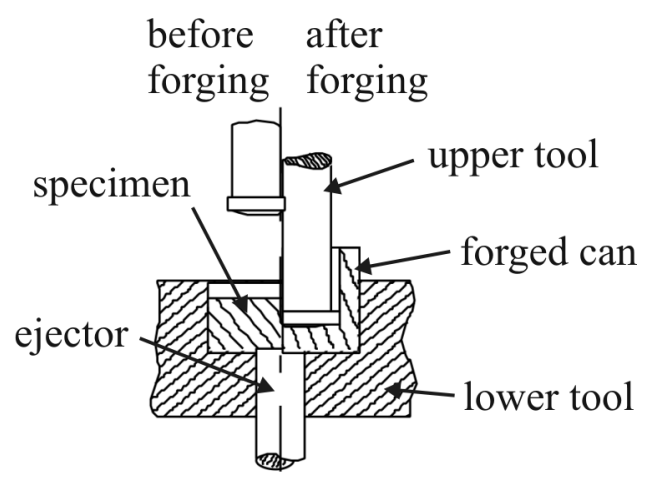

Fig. 6: Sketch of the principle: Backward cup extrusion

To aid the execution of the BCE experiments, a tool set, made out of cold working-steel was inserted. Furthermore a heat-able lower tool was used to analyze the influence of a temperature gradient within the specimen on the phase transformation. Moreover, during the realization of the experiments, the rate of forming, the forming degree and the temperature of the specimen were varied. Each material was tested using a selected set of different parameter variations. The applied parameters are presented in Table 2. The influence of the forming degree was examined in two steps with a forming path of 1 or respectively $2 \mathrm{~mm}$ (Fig. 7). Mechanical end-stops were used in the tool guiding frame to ensure repeating accuracy. The analysis of the martensite content followed on account of magnetic field measurements with a Feritscope, as well as with the help of metallographic analyses. 
Table 2

\begin{tabular}{|l|l|l|}
\hline Forming velocity & $\dot{\varphi}[\mathrm{mm} / \mathrm{s}]$ & $1 ; 5$ and 10 \\
\hline Forming path & $S[\mathrm{~mm}]$ & 1 and 2 \\
\hline Temperature of the specimen & $T\left[{ }^{\circ} \mathrm{C}\right]$ & $-5 ; 20$ and 50 \\
\hline Temperature of the forming tool & $T\left[{ }^{\circ} \mathrm{C}\right]$ & $20 ; 50$ and 100 \\
\hline
\end{tabular}

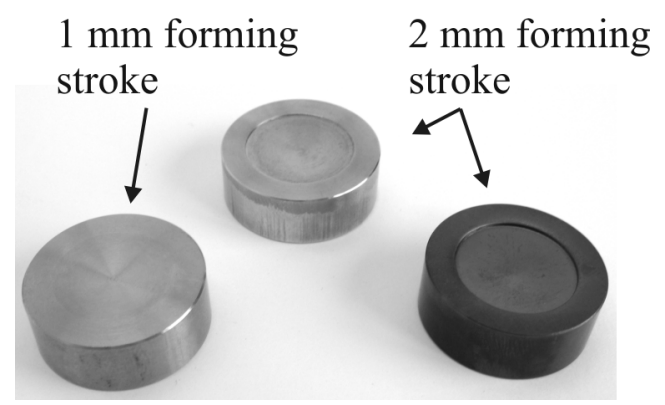

Fig. 7: Specimens of the backward cup extrusion process

Due to the restricted forming ability of stainless steels at low temperatures, a process chain made up of hot and cold forming was chosen in order to realize the production of a demonstrator part. The tool system, together with the tool guiding frame from earlier experiments, as well as additional tool sets, were used as the basic frame for these experiments. In the first hot forming step a pre-form of the knot-element was produced. The tool system was heated up before the beginning of the experiment at $T=200{ }^{\circ} \mathrm{C}$. The thermal expansion of the tools that occurs as a result was already considered in the construction phase, and the die geometry had been thereby appropriately rectified. The specimens, measuring $30 \mathrm{~mm}$ in diameter and $27.8 \mathrm{~mm}$ in height, were heated up in an oven at $T=1100{ }^{\circ} \mathrm{C}$. For the forming process, the press' maximal velocity of $v=30 \mathrm{~mm} / \mathrm{s}$ was used in order to prevent the specimen from cooling down intermediately. By adjusting of the end-stops, the formfilling of the dies was accomplished. For the following experiments, 30 pre-forms were produced.

Within the adjoining cold forming process, various forming degrees shall be introduced into the different component areas, so that local influence of the material and the component properties can be actualized. According to the results from the upsetting tests, a low rate of forming of $v=1 \mathrm{~mm} / \mathrm{s}$ was selected. The completed components were to be metallographically analyzed. Forged components continued to be made available to other sub projects. The goal is a connection of single local property-adjusted parts to a demonstrator component.

\section{Results}

The results aimed for in the first time period, are distinguished as a consequence of new research angles of martensite formation.

Within the scope of basic research in the field of sheet-metal forming, what followed was the analysis of the rolling direction dependence, next to the classic material characterization of the materials (EN 1.4318, EN 1.4301, TRIP) utilized. The development of a calibration for the eddy current measuring device was necessary for the ascertainment of the martensite contents. Especially noteworthy is the new development of FC diagrams, which for the first time, offers the possibility of material characterization of structured sheet metals.

The analysis regarding the phase transformation as well as the structure examination within metastable, austenitic sheet steels includes the frequency and temperature analysis, the structural field analysis, as well as structural analysis by using the Nakajima test, and the demonstrator development. Furthermore, as a result, tool development was directed towards the careful 
manufacturing of local $\alpha$ '-martensitic structures. The subsequent analysis includes the examination of the deep-drawn u profile, with optical (deformation change analyses by means of Vialux), acoustic and radiographic methods (internal stress analysis, by means of X-ray diffractometer).

To support the conducted tool construction within the sheet metal and solid fields (details in 28), simulation calculations, were carried out with the help of the Finite Element Analysis (FEA). The aim of this simulation, next to the process design, is to use the parameter determination in order to produce a stronger hardening as a consequence of high $\alpha^{\prime}$-martensite content. Furthermore, the material model, after Springub [22] was extended for the use in 3D volume elements.

Regarding solid components, the dependence of the martensite content in the experiments on the forming parameters was able to be analyzed on the basis of the upsetting tests. Next to the material 1.4301, further chrome nickel steels and the manganous hard steel 1.3401 were examined regarding transformation-induced martensite formation under compressive stress. The evaluation followed under particular consideration regarding the influence of temperature and forming degree.

The quantification was carried out with martensite measurements from the Feritscope and Magnatest. Metallographic and numeric analyses were called upon to be equalized. The first step towards the conversion of the transformation-induced martensite formation into the massive forming, took place according to BCE. In regard to martensite formation, it is particularly interesting that next to the compressive stress that takes place during forging within the area of free surface, tensile stress also arises. In addition, the process is influenced by acutely directed temperature control.

\section{Martensite in Sheet-Metal}

Material Characterization and Investigation on Rolling Direction. Standardized flat tensile tests, after DIN EN 10002 [DIN91, DIN98] bearing angle positions of $0^{\circ}, 45^{\circ}$ and $90^{\circ}$ to rolling direction of the sheet metal, were pulled until failure point, and the force-displacement and transverse elongation were recorded in a single axle tensile test after DIN EN 10130 on a hydraulic universal-tester DynaMess S100/ZD. As a consequence, the stress/strain-extension diagrams, the flow curves and the uniform elongation $\mathrm{A}_{\mathrm{gl}}$ were examined for the materials EN 1.4301, EN 1.4318, EN 1.4372 und TRIP780. To obtain more information as regards the deep-drawing behavior, forming limit curves in Nakajima experiments were analysed with the help of the Erichsen-type system. The four metastable austenitic materials were consequently able to be descriptively compared as regards their major $\varphi_{1}$ and their minor $\varphi_{2}$ strain. In Fig. 8, the results of this experiment are graphically contrasted. The sheet metal thickness of all materials used was $s_{0}=1.0 \mathrm{~mm}$. 


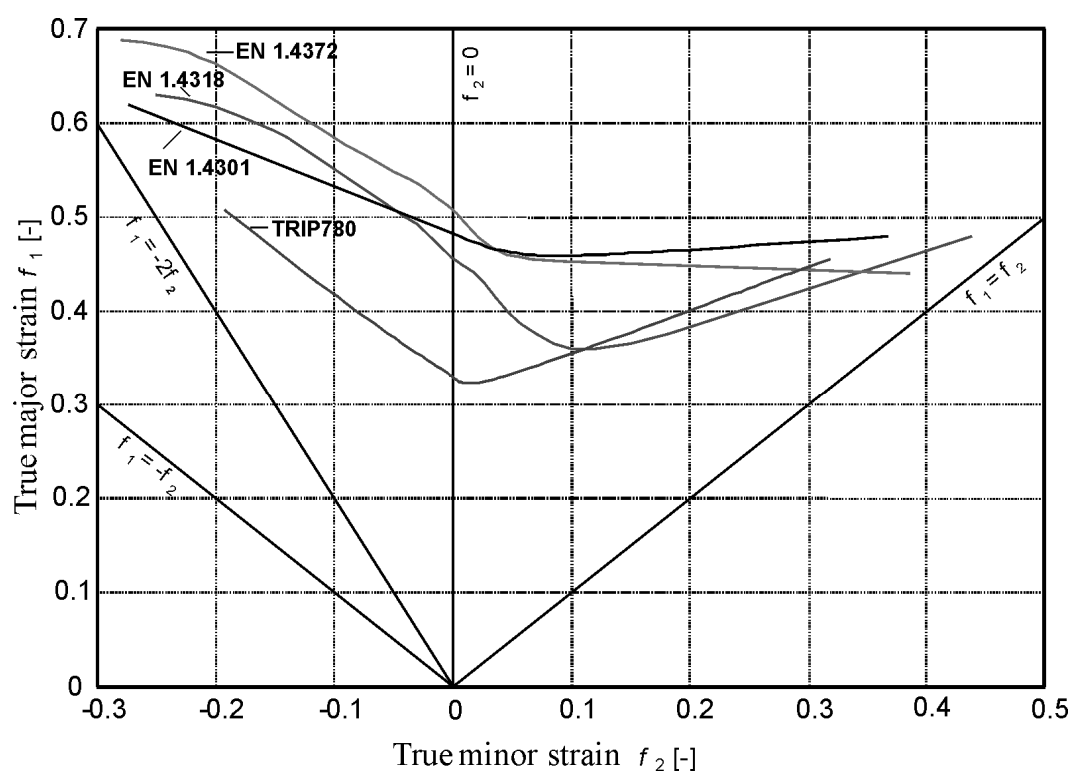

Fig. 8: Forming limit curve of the materials EN 1.4301, EN 1.4318, EN 1.4372 and TRIP780

The previously researched material parameters (see detail 25, 26, 27, 29) form the approach angle regarding the evaluation of the future structural experiments, as well as the foundation of numerical analysis.

First tests towards analyzing the area of influence of the transformation-induced $\alpha^{\prime}$-martensite transformation, were carried out by utilizing the material EN 1.4301. Round dishes of $d=100 \mathrm{~mm}$ in diameter were produced with a hydraulic press in an available deep-drawing die. These dishes demonstrate varying stress states as a result of differing material expansion, which in turn exhibits $\alpha^{\prime}$-martensite content. With the help of the Feritscope, the deep-drawing components were measured starting from the ground to the flange on account of their Ferrite content and their localized sheet-metal thickness. Consequently, the martensite content was determined. During the process, the $\alpha^{\prime}$-martensite development demonstrates (Fig. 9) a distinctly stronger instance at $90^{\circ}$ to the pitch direction than at $0^{\circ}$ in the rolling direction [5]. Both curves show a distinct rise in the phase conversion within the range of the cup wall and the flange, whereby a particular factor of influence in the structure accumulates in the pitch direction, the latter being conditioned by the material's anisotropy.

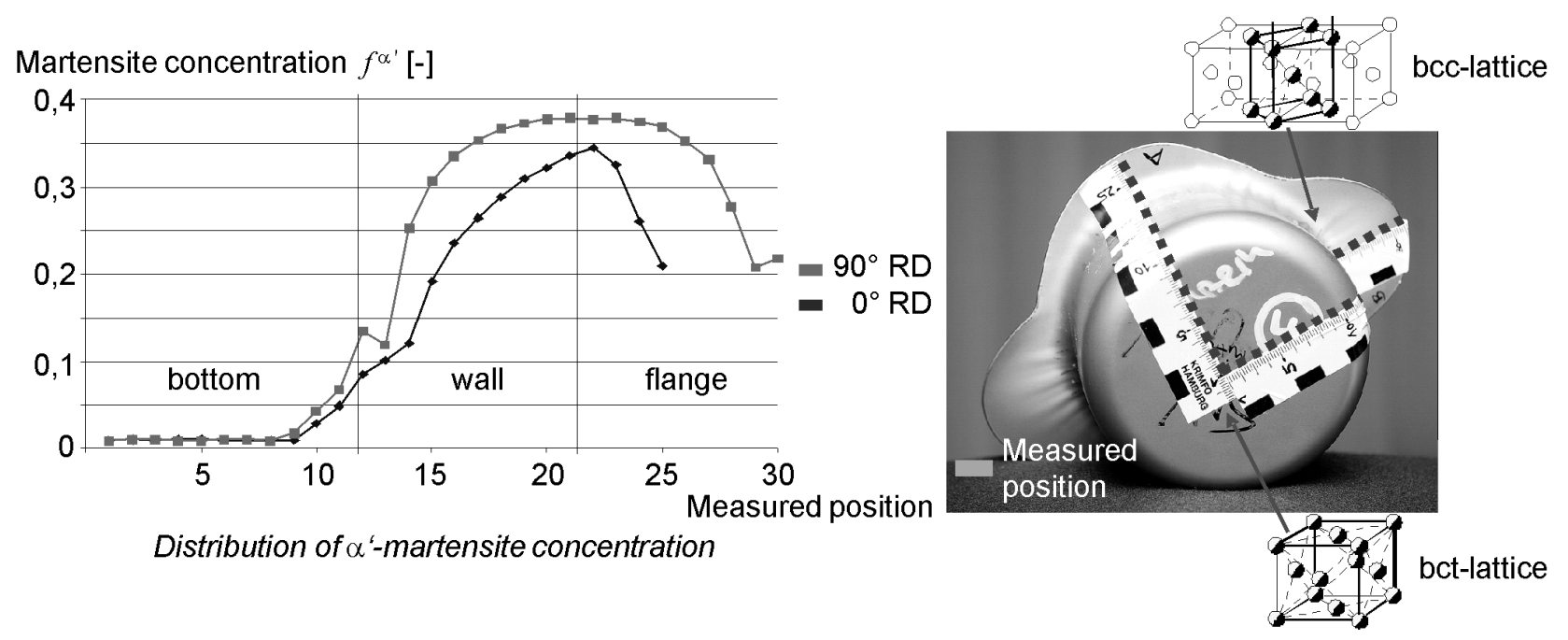

Fig. 9: The course of the $\alpha^{\prime}$-martensite content from the ground to the flange of the rotation symmetric dish, presented on the right, for different pitch directions 
Calibration of the Eddy Current Reading. The eddy current measuring device Magnatest D 3.623, of the company Förster, which was acquired within the scope of CRC project, was used in order to achieve a simplification of $\alpha^{\prime}$-martensite examination. The device enabled the installation and programming of test definitions, which would test the structural composition of various materials. As opposed to the Feritscope, it would be possible to test ferrite material as for example TRIP steel. The installation of a test definition requires a variety of testing material and reference test values, for example from metallographic examination or Feritscope readings. The measuring results of the testing materials were assessed regarding their signal strength and an eventual harmonic analysis of the first harmonic, under different frequencies with the Magnatest $(2,4,8,16$, $32,64,128,256,512,1024 \mathrm{~Hz}$ ). Next, the division into different sorting limits (A and B ranges) followed. In doing this, the tuning of the testing parameters followed, as well as the weakening of the signal $(\mathrm{dB})$, the sensitivity of the search coil $(\mathrm{dB})$ and the evaluation of the high harmonics [-]. In order for this eventuality to take place, high ferrite contents must be within the reading signal. To extend this testing definition onto low $\alpha$ '-martensite content, a testing definition is to be compiled that forgoes the harmonic analysis. The calibration of the Magnatest was able to be actualized for the previously examined stainless steel materials EN 1.4301, EN 1.4318 und EN 1.4372. As regards the TRIP steel RA-K 47/78, the compilation of a test definition is currently in progress. Due to the ferromagnetic zink coating, a signal differentiation in the basic structure is not possible by implication.

Forming Curves. As a result of the new procedure of forming curves a comparability of structured and unstructured Nakajima tests could be developed. With that, the occurring deformations would be analyzed not only in regards the place of failure, but also in regards to the part of structured regions. In consideration of the differences in the samples' various molded bulgeheights between structured and unstructured material, a 3D diagram can be compiled dealing with the limit of alteration of shape. This illustrates the interdependency of the major $\varphi_{1}$, the minor $\varphi_{2}$ strain and the bulge height $h_{\mathrm{B}}$. The form alteration behavior of structured samples can therefore be characterized for the first time. Preliminary tests on temperated tensile tests and deep-drawn components created the basis for the development of deep-drawn components which are heat-able and cool-able, and intended for temperatures of between $T=-30^{\circ} \mathrm{C}$ until $T=100^{\circ} \mathrm{C}$. This temperature range had been actualized as a result of compressed-air-powered refrigerating generators (Vortex-Tubes) which directly cool the blank, as well as the heating cartridge, in order to partially heat a press-segment [25]. As additional forming-elements for the introduction of structuring, round as well as ellipsoidal elements were developed which facilitated the increase in the forming degree. As a result, the enhancement of the hardness and with that the solidity could be ascertained, taking place at the constant forming degree and a tempering of $T=-20^{\circ} \mathrm{C}$. Here, the material EN 1.4301 displayed the highest martensite increase of over $100 \%$, compared to $T=20^{\circ} \mathrm{C}$, whilst the material EN 1.4318 exhibited the highest conversion-tendency of the austenitic phase. The martensite formation in stainless-steels could only be close to completely suppressed at temperatures above $T=80^{\circ} \mathrm{C}$ and at a forming-degree of up to $\varphi=0.15[-]$, as the effect of the forming-degree is more distinctive on the martensite formation than that of the temperature. Details are to be found in $[26,11]$.

Structural Field Analysis. In order to analyze the advantages of the structures more precisely, tensile-test- geometries, after DIN 10002, part 2, were produced and provided with four different structurings (Fig. 10). To accomplish these tests, the assessment in a single-axle tensile-test took place according to DIN 10130, in order to examine the effects of the material behavior on the basis of the strain-stress course and the flow curve respectively. For these experiments, the steels EN 1.4301, EN 1.4318, EN 1.4372 and TRIP780 were observed. 


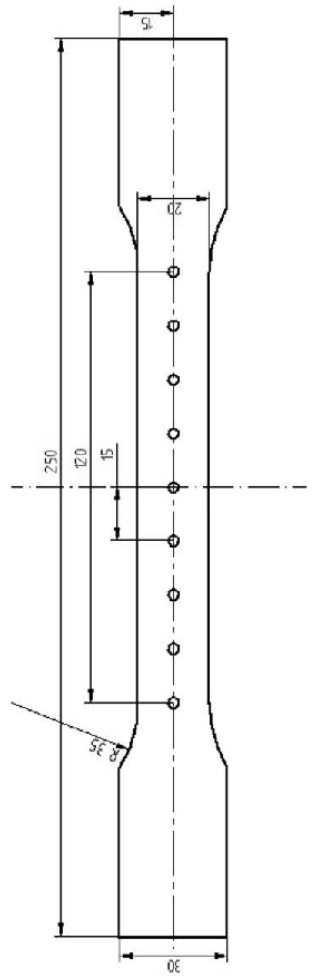

1)

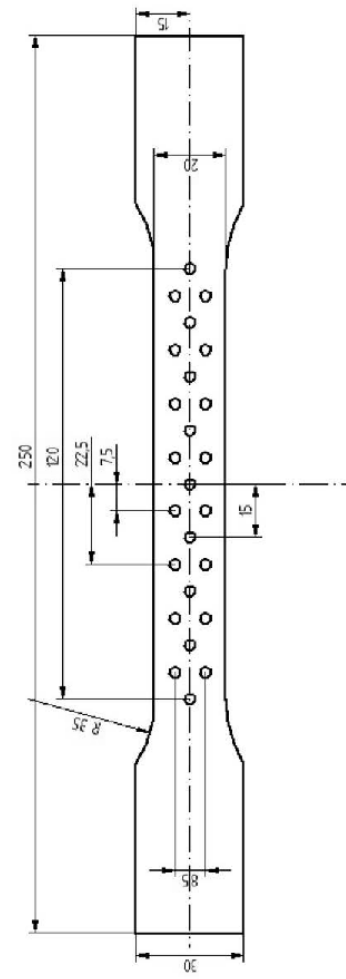

2)

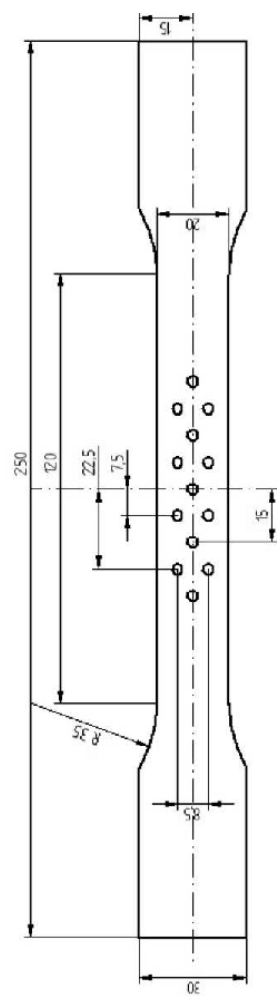

3)

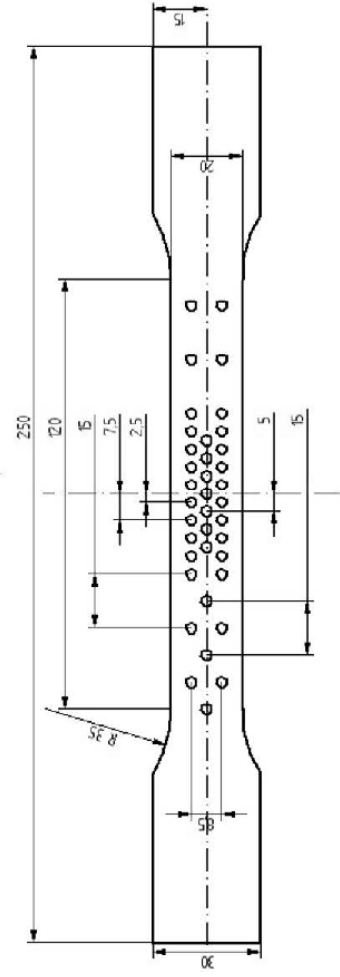

4)

Fig. 10: CAD-Image of the four different structurings inserted

The aim of the structural selection was to quantify the effect of various structuring and to consequently quantify the different $\alpha$ '-martensite content as well. While structure 1) exhibits a mere few structural points in a row, structure 2) was equipped with a three row symmetrical structure. Structures 3) and 4) should demonstrate whether a certain alignment of the structures can create an additional crack-behavioral effect, as for example a crack dislocation on the outer regions of the experiment's gauge length. In Table 3 to Table 6, the data from the single-axle tensile-test are presented in detail for the base material (without structures) and the different structures of the examined materials.

Table 3: Data from the single-axle tensile-test for the material EN 1.4301

\begin{tabular}{|c|c|c|c|c|c|}
\hline & $\begin{array}{c}\text { Base Material } \\
\mathbf{9 0}^{\circ} \text { rolling direction }\end{array}$ & Structure 1 & Structure 2 & Structure 3 & Structure 4 \\
\hline $\boldsymbol{R}_{\mathbf{p 0 , 2}}$ & 247.9 & 282.3 & 269.37 & 307.43 & 309.37 \\
\hline $\boldsymbol{R}_{\mathbf{m}}$ & 699.9 & 676.03 & 689.23 & 685.97 & 682.8 \\
\hline $\boldsymbol{A}_{\mathbf{G l}}$ & 48.1 & 48.9 & 48.6 & 38.77 & 36.53 \\
\hline $\boldsymbol{r}$-value & 1.08 & 0.835 & 0.756 & 1.832 & 2.57 \\
\hline $\boldsymbol{n}$-value & 0.42 & 0.401 & 0.396 & 0.392 & 0.37 \\
\hline
\end{tabular}

Table 4: Data from the single-axle tensile-test for the material EN 1.4318

\begin{tabular}{|c|c|c|c|c|c|}
\hline & $\begin{array}{c}\text { Base Material } \\
\mathbf{9 0} \text { rolling direction }\end{array}$ & Structure 1 & Structure 2 & Structure 3 & Structure 4 \\
\hline $\boldsymbol{R}_{\mathbf{p 0 , 2}}$ & 446.3 & 426.9 & 470.0 & 480.0 & 442.6 \\
\hline $\boldsymbol{R}_{\mathbf{m}}$ & 807.87 & 807.7 & 824.97 & 810.63 & 814.87 \\
\hline $\boldsymbol{A}_{\mathbf{G l}}$ & 42.5 & 43.07 & 42.37 & 34.4 & 34.8 \\
\hline $\boldsymbol{r}$-value & 1.01 & 0.995 & 0.788 & 2.112 & 3.288 \\
\hline $\boldsymbol{n}$-value & 0.36 & 0.334 & 0.331 & 0.355 & 0.334 \\
\hline
\end{tabular}


Table 5: Data from the single-axle tensile-test for the material EN 1.4372

\begin{tabular}{|c|c|c|c|c|c|}
\hline & $\begin{array}{c}\text { Base Material } \\
\mathbf{9 0} \text { rolling direction }\end{array}$ & Structure 1 & Structure 2 & Structure 3 & Structure 4 \\
\hline $\boldsymbol{R}_{\mathbf{p 0 , 2}}$ & 421.57 & 421.1 & 483.57 & - & 450.23 \\
\hline $\boldsymbol{R}_{\mathbf{m}}$ & 775.23 & 769.57 & 781.1 & - & 780.93 \\
\hline $\boldsymbol{A}_{\mathbf{G l}}$ & 47.3 & 44.67 & 42.8 & - & 33.47 \\
\hline $\boldsymbol{r}$-value & 0.82 & 0.89 & 1.078 & - & 2.456 \\
\hline $\boldsymbol{n}$-value & 0.32 & 0.298 & 0.278 & - & 0.27 \\
\hline
\end{tabular}

Table 6: Data from the single-axle tensile-test for the material TRIP780

\begin{tabular}{|c|c|c|c|c|c|}
\hline & $\begin{array}{c}\text { Base Material } \\
\mathbf{9 0} \text { rolling direction }\end{array}$ & Structure 1 & Structure 2 & Structure 3 & Structure 4 \\
\hline $\boldsymbol{R}_{\mathbf{p 0 , 2}}$ & 437.6 & 431.83 & 462.9 & 433.33 & 425 \\
\hline $\boldsymbol{R}_{\mathbf{m}}$ & 782.7 & 763.47 & 784.1 & 777.43 & 779.53 \\
\hline $\boldsymbol{A}_{\mathbf{G l}}$ & 19.3 & 16.7 & 15.8 & 15.27 & 13.85 \\
\hline $\boldsymbol{r}$-value & 0.85 & 0.852 & 1.27 & 1.095 & 1.517 \\
\hline $\boldsymbol{n}$-value & 0.21 & 0.188 & 0.161 & 0.181 & 0.16 \\
\hline
\end{tabular}

On the basis of this data, a consistent tendency for all examined steels becomes clear, namely that the insertion of the structures leads to a decline of the flexural strength. The effects of the structural degree can be clearly observed within the progression of the curve in the stress-strain diagram. It can be basically and essentially acknowledged that the tensile-test geometries, bearing the inserted structure of examined stainless-steels, exhibit flow curve increase, whereas the TRIP780 demonstrates a stress increase resulting in an elongation until approximately $\varepsilon=8 \%$. The stressstrain curves for the material in its original state, as well as for the material bearing different structuring, are presented in the following, exemplified by the stainless-steel; EN 1.4301 (Fig. 11) and TRIP 780 (Fig. 12).

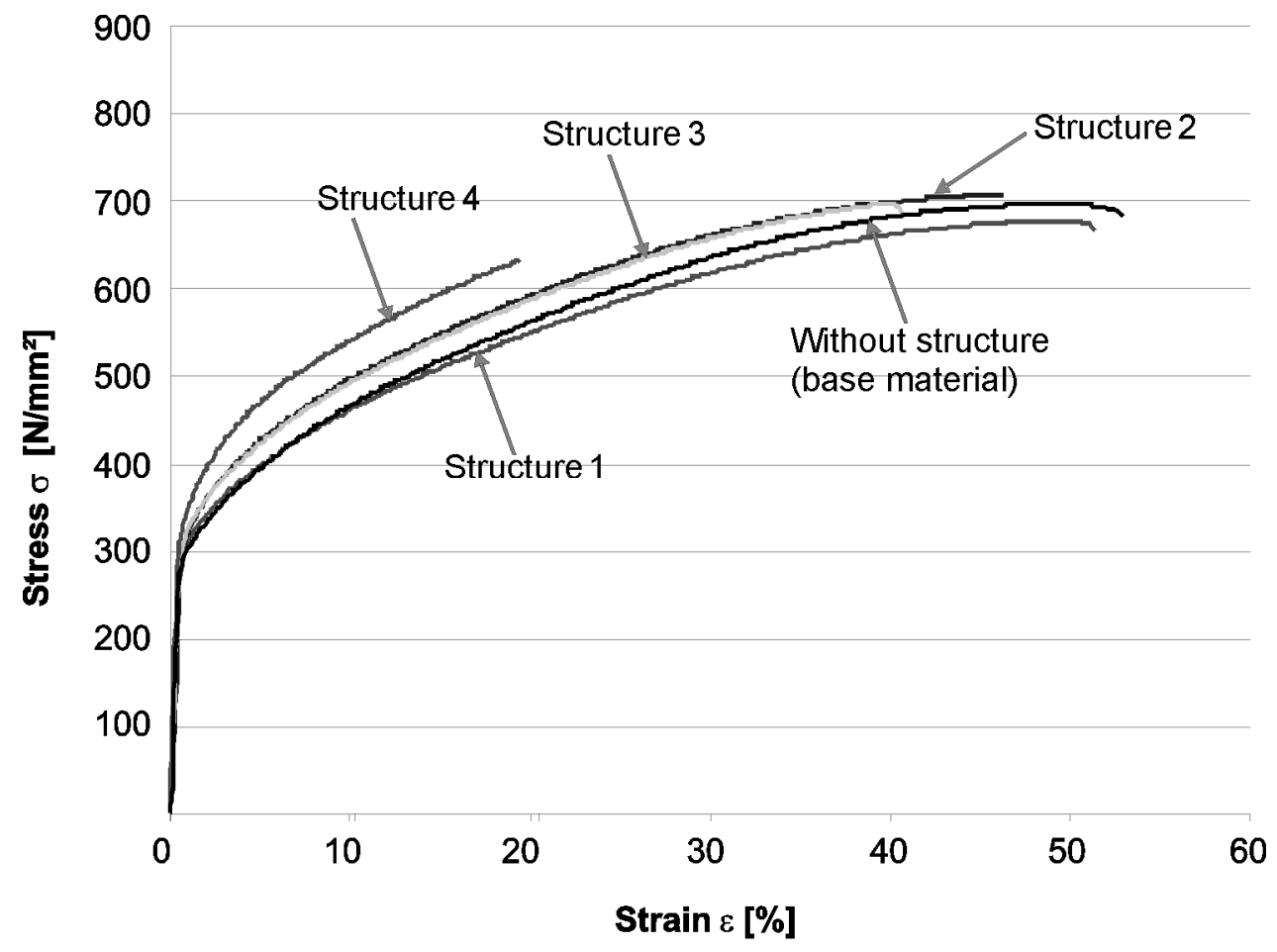

Fig. 11: Stress-strain diagram for the stainless-steel EN 1.4301. Original condition as well as imagined structuring 
Based on the curve progression, the decrease in flexural strength, dependent on the structuringdegree is clearly visible. Structure 4 exhibits the highest curve-progression until test-failure. Under expansion values of up to $\varepsilon=25 \%$, structures 2 and 3 demonstrate higher values than by the unstructured test as well. The test in its original condition, demonstrates at commencement, a close to identical course (up to $\varepsilon=10 \%$ ) as observed in the example of structure 1 . Towards material EN 1.4301, one can summarize that the insertion of many structural-points, as in structure four, a solidity strengthening as well as simultaneous minimization of the flexural strength takes place, as a result of transformation-induced $\alpha$-martensite formation. The material EN 1.4318 on the other hand, exhibits a plateau within the expansion range of $\varepsilon=10 \%$ until $\varepsilon=20 \%$.

In Fig. 12, the stress-strain progressions of the remaining austenitic steel TRIP780 are presented, depicting the different structural-parameters. An improvement of the material behavior, as a result of the structuring, only occurs at an expansion of approximately $\varepsilon=8 \%$, at higher expansion values, the material exhibits no increase in stress as opposed to the original material. The reason for this is presumed to be the differing mechanism of consolidation, for which the transformation induced $\alpha$-martensite development is responsible. Unlike in the example of the stainless-steels bearing a pure austenitic matrix, this material possesses a remainder austenite share merely of approximately $15 \%$, which is available to the conversion.

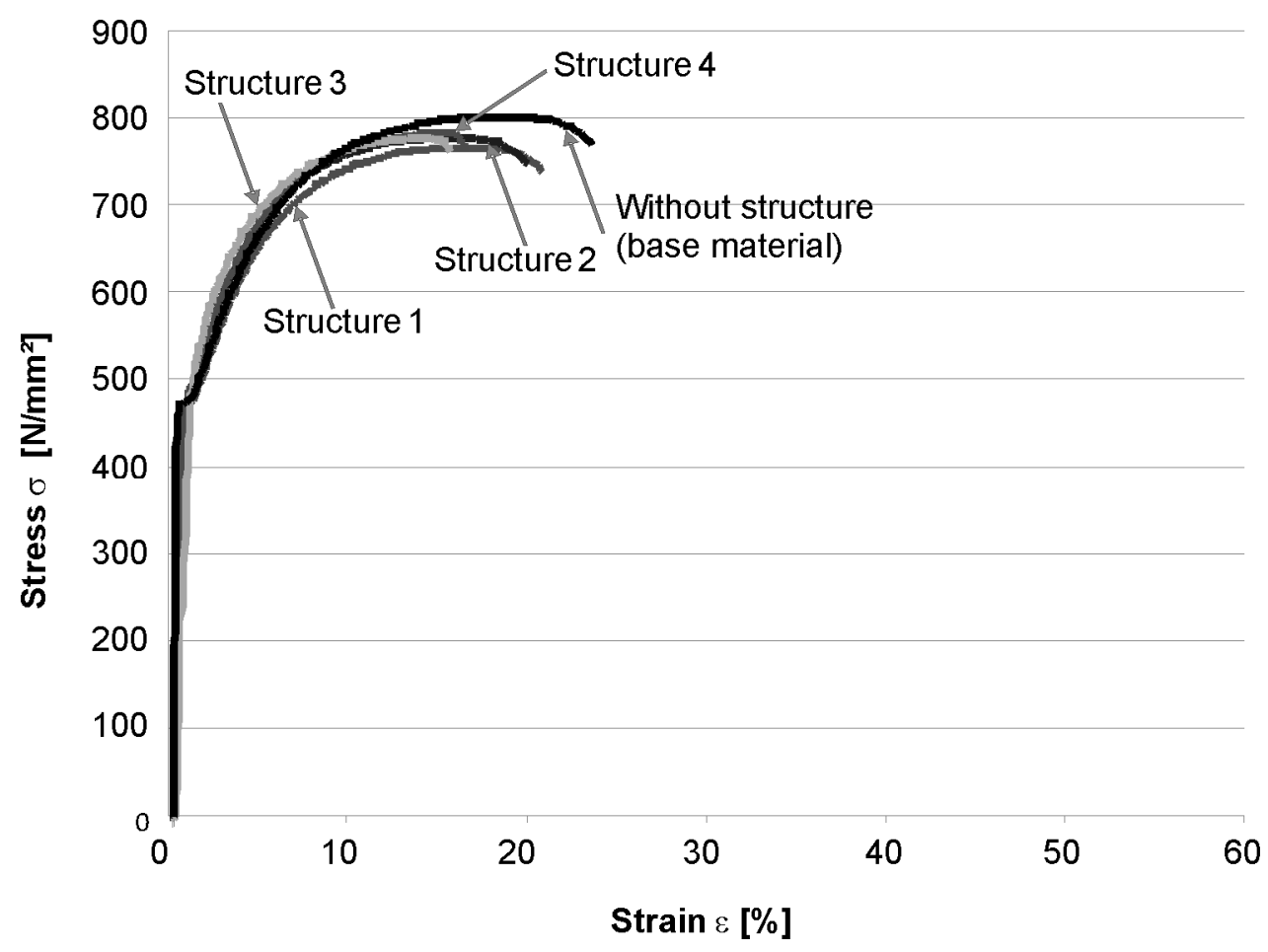

Fig. 12: Stress-strain diagram for the steel TRIP780. Original condition and previously presented structuring

\section{Structural Analysis based on a Demonstrator Component.}

Simulation Calculations for Interpretation. In support of the conducted tool construction (details in [28]), accompanying simulation calculations, aided by the Finite Element Analysis were carried out. An objective of this simulation is to survey the faultless production. With the help of numerical calculation, component areas are to be further detected, in which an increased $\alpha$-martensite formation for the material EN 1.4301 can be expected.

First, the examining of separate additional forming-elements took place. In aid of this, a $5 \times 5 \mathrm{~mm}$ sheet-metal blank was discretized over the sheet-metal thickness of $1 \mathrm{~mm}$, with twelve 3D volume elements (Hexa). In doing so, the cross-linking in the region of the prestrain was improved. The tool components (die, blank holder and bolster) were either recorded with rectangular shellelements or analytically. These models could be used in the analysis of the punch variations 
(Fig. 13). Within the scope of these experiments, the variation of the radiuses, the punch-peak, and the forming method followed. The assessment was carried out particularly by the means of maximal principle stress, the forming degree, the martensite content and the sheet-metal thickness. Regarding these experiments, the material model described in [22] was extended in terms of the volumeelement-description, and was used to calculate the martensite content.

Within the scope of the experiments it has been made apparent that the deep-drawing process is the process by which means, the most tensile-stress can be introduced into the additional formingarea. Therefore, with this forming process, the highest martensite content can be attained. Another advantage is the large surrounding area within the forming zone. This large impact leads to the desired localized strengthening.

Further results of the analyses include that as a consequence of larger punch-geometries (for instance oval punchs or larger punch radiusses) of a longer forming process, the martensite content in the localized forming zone can be increased and the impact range extended.

material: X5CrNi18-10

$s=1.0 \mathrm{~mm}$ : initial thickness

$t_{r}=2.0 \mathrm{~mm}:$ die radius

$l_{M}=0.0 \mathrm{~mm}$ : cutting plane

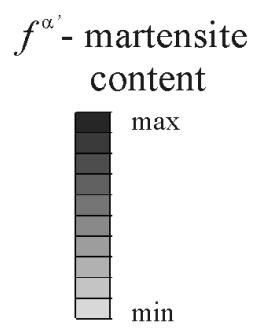

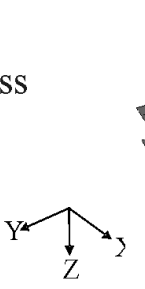

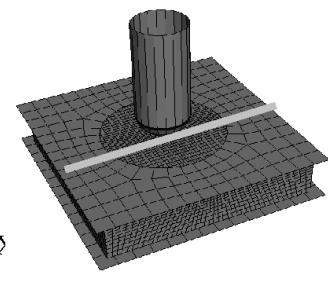

deep drawing round punch
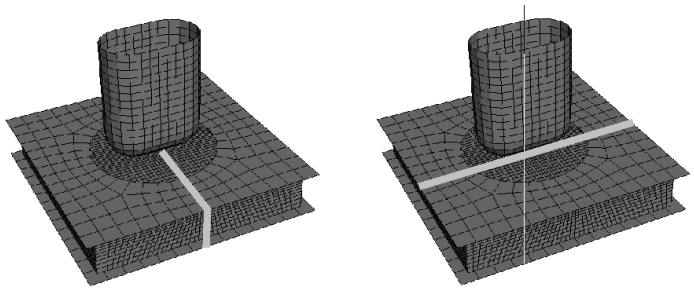

deep drawing ovale punch

$$
\begin{aligned}
& \text { depth } \\
& t_{S t}=0.25 \mathrm{~mm}: \\
& t_{S t}=0.37 \mathrm{~mm}:
\end{aligned}
$$
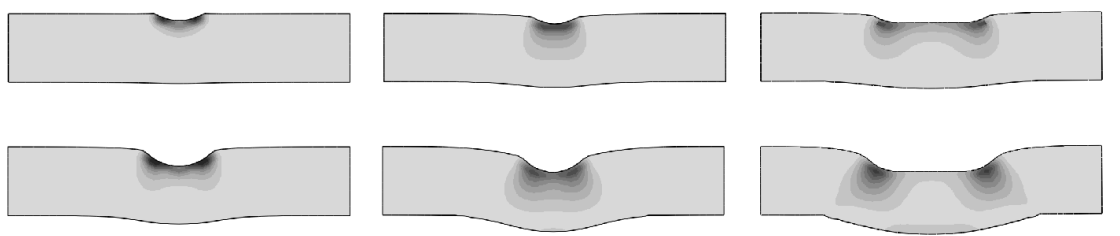

Fig. 13: Analysis of the punch radiuses regarding the martensite content

For the commercial FE system Abaqus/Explizit, a simulation model which illustrates the forming process of the U-Profile has also been developed. The tool-active surfaces, in particularly the additional forming-elements, are to be illustrated yet simplified thru the use of fixed shell-elements. The discretization of the blank is to be achieved by the use of shell-elements. The material's forming-behavior is to be illustrated with an elastic-plastic constitutive equation, taking the plastic anisotropy into consideration, whereupon a temperature dependency of the flow curve is neglected. At this point, a calculation of the resilience, after the component has been removed is to be forgone. In the following, simulation results for the material EN 1.4301 exemplified with a round geometry of the additional forming-elements are exemplarily presented. The here presented basic statements are nevertheless generally transferrable onto other materials and the multi radii-additional formingelements.

In examining the sheet-metal thickness distribution, it is discernable that outside of the impact area of the additional forming-elements, there is no significant decrease in sheet-metal thickness (Fig. 14). This impact area is merely inessentially larger than the additional forming-elements themselves. Within the area of the additional forming-elements, the localized minimum of the sheetmetal thickness $s$ lies at a value of $s=0.8 \mathrm{~mm}$. This corresponds with a relative sheet-metal decrease of approximately $20 \%$ and lies therefore within the maintainable realm of sheet-metal forming processes. 
sheet thickness
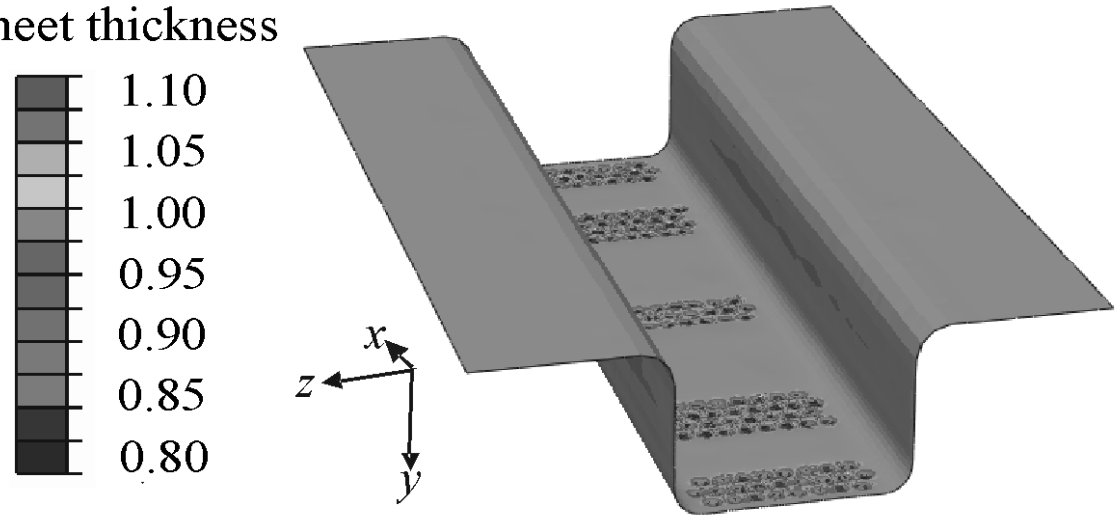

Fig. 14: Calculated sheet-metal thickness distribution of the U-Profile

Within the examination of the forming-degree-distribution, the localized impact of the component as a result of the additional forming-elements becomes distinctly clear (Fig. 15). Forming degrees of up to $\varphi=0.8$ [-] emerge within the base regions, while in the remaining component area, hardly any forming takes place. Because a significant influencing factor on the $\alpha$ '-martensite formation is in fact the forming degree, a high increase of $\alpha^{\prime}$-martensite content is to be expected in close proximity to the additional forming-elements. Also, depending on the increase of the forming degree, an increase of phase conversion within the flange area is to be expected.

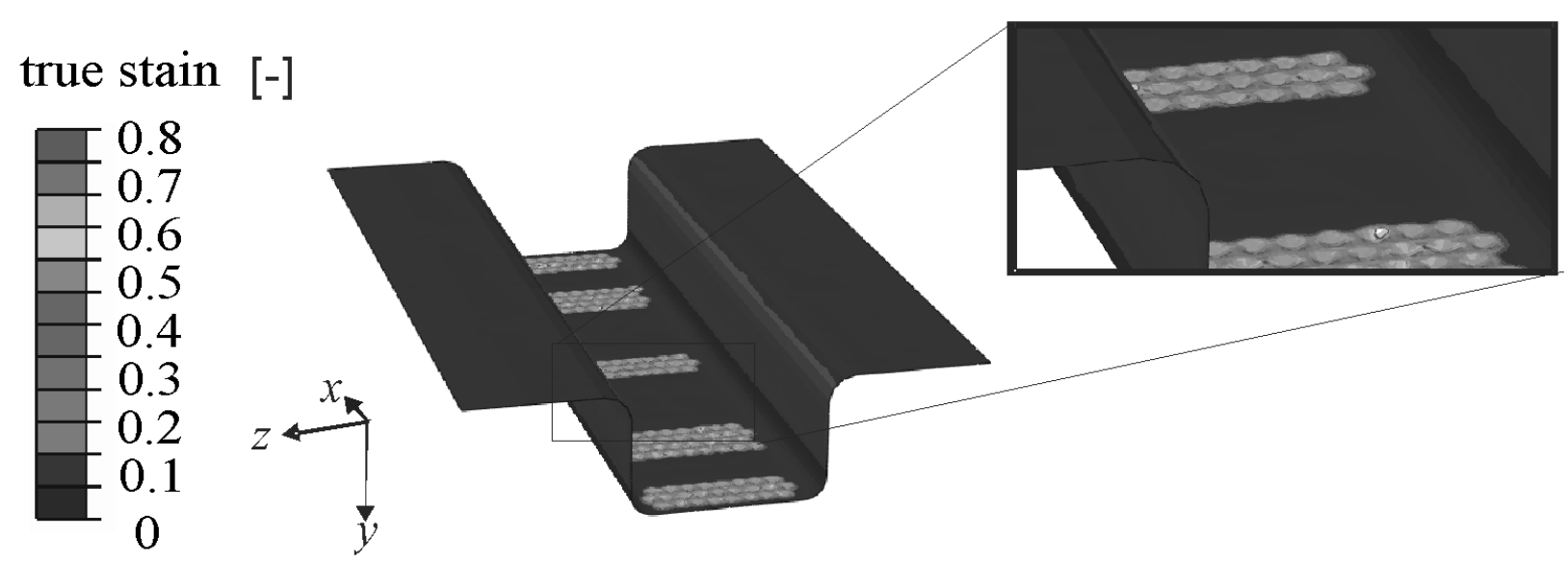

Fig. 15: Calculated forming degree of the U-Profile

The illustrated calculation results exhibit the basic potential of the tool system, to purposefully and locally modify the material behavior, following the phase transformation. Although the additional forming-elements have only a very small area of impact, an increased strengthening in selected areas can be adjusted as a result of defined $\alpha^{\prime}$ - martensite portions. The impact of the temperature control system is still to be analyzed in experimental analyses.

Analysis of Increased Strengthening. In order to analyze the $\alpha$ '-martensitic structures regarding their increased strengthening effect, and with that their energy absorption, crash tests in a test bed were carried out at the Institut für Dynamik und Schwingungen of the Leibniz Universität Hannover (LUH). To this effect, crash-demonstrators in Double-Z-Profile were used, which were based on the construction of a crash box (Fig. 16). Continued analyses as well as the construction of a tool were carried out with the Double-U-Profile. 

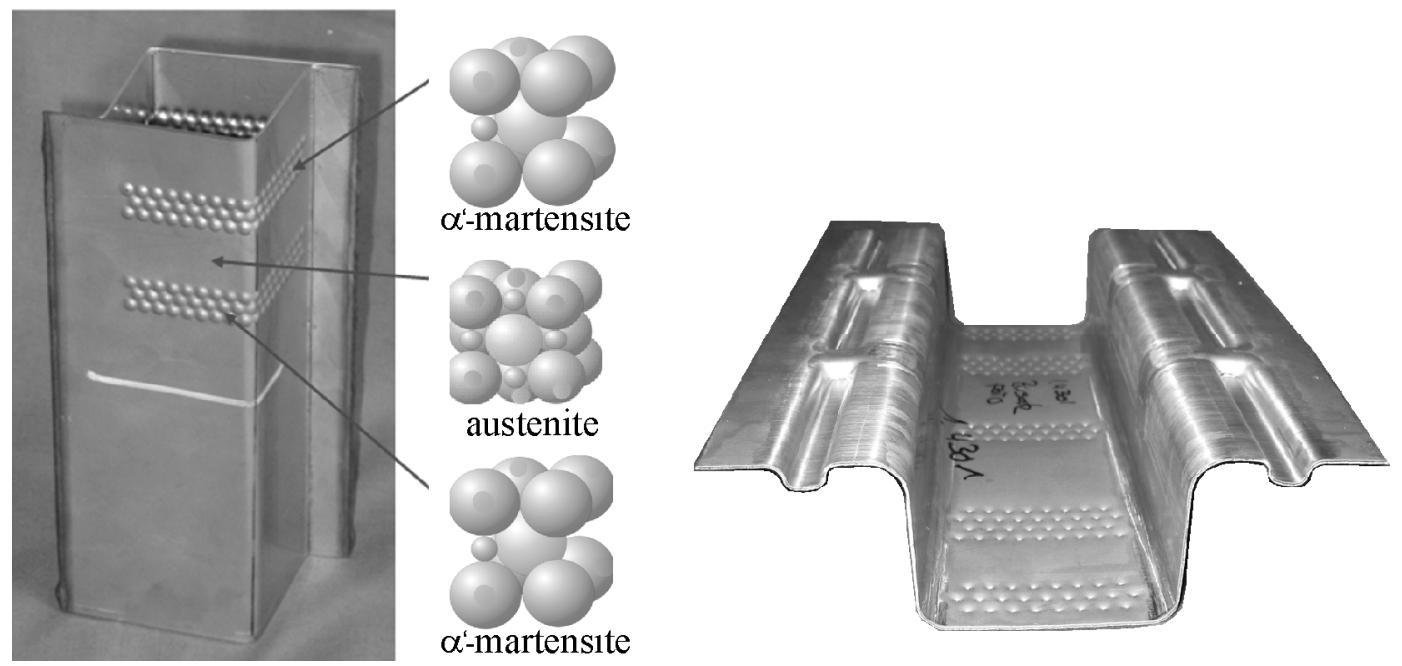

Fig. 16: Crash demonstrator in Double-Z-Profile as well as U-Profil with $\alpha^{\prime}$-martensitic structuring in an austenitic structure using the material EN 1.4301

In order to accomplish the construction of the demonstrator's Double-Z-Profile, one triple rowed structural arrangement was respectively inserted into the rectangular sheet-metal cut-outs using the deep-drawing die. Next, the blanks were bent into the $\mathrm{Z}$ form and, by means of the electron beam welding process, connected to one another. This assembly was carried out similarly for the unstructured blanks in order to ensure the achievement of comparability between unstrengthened and structured demonstrators.

For the test set-up, a mass of $m=100 \mathrm{~kg}$ and a drop height of $h=4 \mathrm{~m}$ were selected. Under the consideration of frictional resistances, the outcome is a speed of $v=8.4 \mathrm{~m} / \mathrm{s}$ and a crash energy of $E=3670 \mathrm{~J}$. In order to evaluate the convolution behavior, the experiments were recorded with a high-speed camera, while the force path was documented by means of a load cell. After a way of $s=160 \mathrm{~mm}$, an additional crash absorber was integrated into the test bed in order to decelerate the falling mass and to avoid damage of the test bed itself. In Fig. 17 , the crash behavior of the unstructured demonstrator is illustrated, based on pictures taken with the high-speed camera.

Based on these pictures, it is clearly visible that the convolution behavior proceeds from the base of the component. After a crash path of $s=160 \mathrm{~mm}$, the experiment has to be aborted as a result of the additional crash-absorber (Fig. 17, image f), because the energy had not been completely absorbed by the demonstrator, and to therefore avoid damage to the test bay. The evaluation of the force-path process demonstrates a small medium force of $F_{\mathrm{m}}<23 \mathrm{kN}$ as well as a maximal force of $F_{\max }=47 \mathrm{kN}$ at commencement.

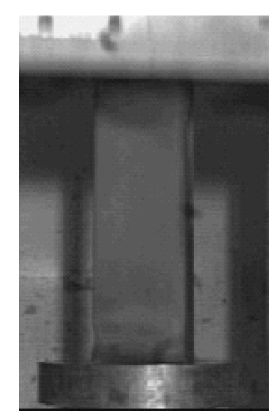

a)

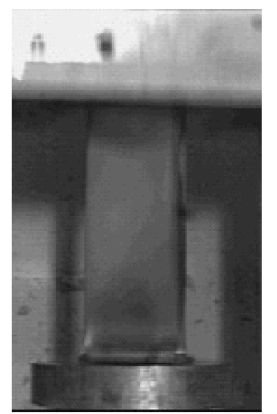

b)

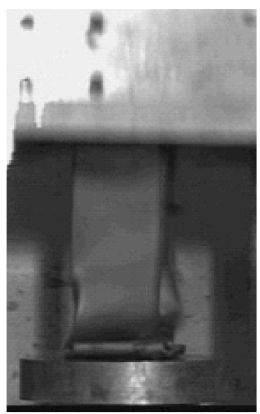

c)

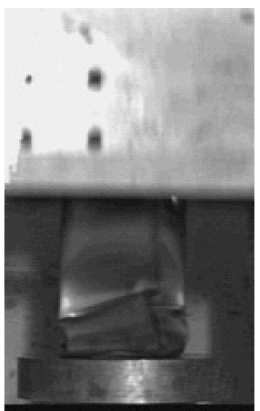

d)

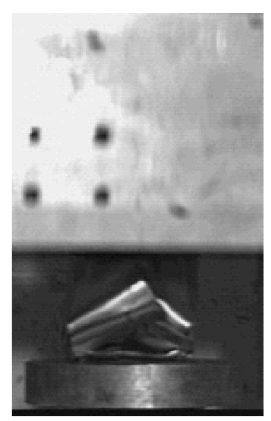

e)

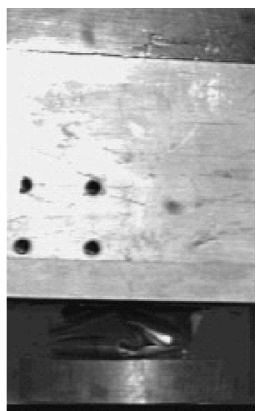

f)

Fig. 17: Crash-course of unstructured demonstrators a) till f)

In comparison, the following images in Fig. 18, taken with the high-speed camera, exhibit the crashcourse for the structured demonstrator. 


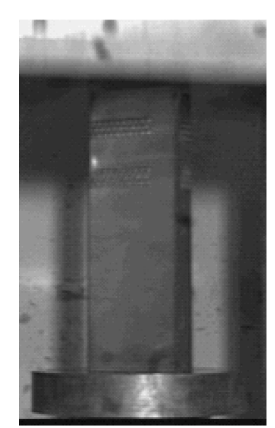

a)

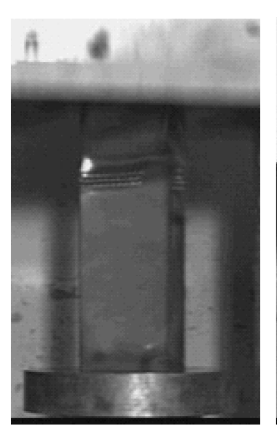

b)

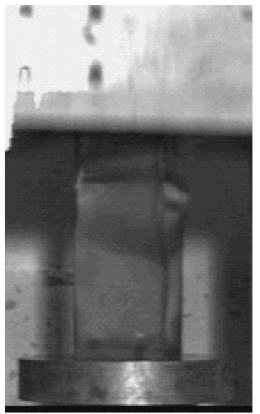

c)

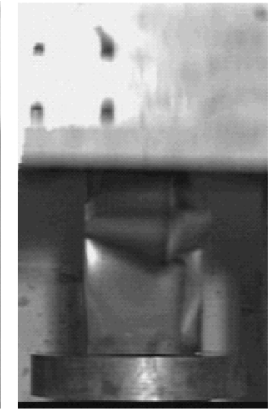

d)

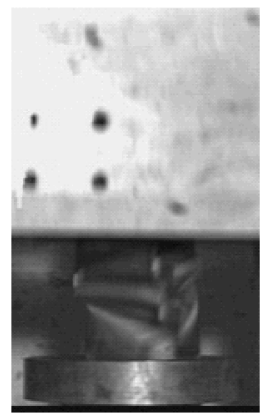

e)

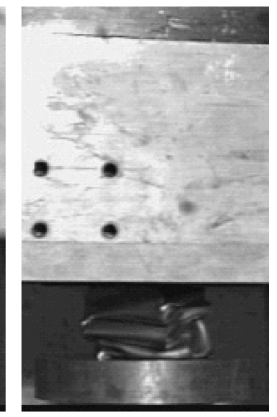

f)

Fig. 18: Crash-course of the structured demonstrator a) till f)

Based on these images, the formation of the first crease is clearly visible within the upper region of the demonstrator, namely is to say between the high strength structuring. Furthermore, it was possible in this experiment to completely absorb the crash energy until a deformation way of $s=146 \mathrm{~mm}$ (Fig. 18, image f). The recorded data exhibit a maximal force of $F_{\mathrm{m}}=43 \mathrm{kN}$ as well as a medium force of $F_{\max }=25 \mathrm{kN}$.

In conclusion, following facts have been established:

- Unstructured as well as strengthened demonstrators exhibit sound crash behavior

- Still, both variants differ fundamentally from one another regarding

- their energy absorption

- their force-path as well as

- their deformation behavior.

- The insertion of localized $\alpha^{\prime}$-martensitic structures in order to strengthen, affects the crash behavior to a large extent.

- After the crash-test, no increase or formation of $\alpha$ '-martensite could be ascertained in either demonstrator variations. It is presumed that this is a result of the forming speed and the thus emerging friction heat.

Internal Stress Analysis using an X-ray Diffractometer. The structures inserted during the forming were analyzed particularly regarding their internal stress. The examination of the tensions was carried out at the Institute for Manufacturing Technology and Tool Machinery and at the LUH, within an X-ray diffractometer. The material TRIP780 and EN 1.4301 were analyzed. In Fig. 19, a part of the results for the oval structures is exemplarily presented. Internal strains were measured in longitudinal and cross direction for various parameters. It can be gathered from the results that the structures primarily cause the contribution of compressive stress. Negative internal strains can work against the emerging of cracks. At a temperature control within the region of $T=80{ }^{\circ} \mathrm{C}$ and $T=100{ }^{\circ} \mathrm{C}$, the compressive internal strain can be increased. In the case of the metastable stainlesssteel EN 1.4301, no increase in internal strain can be achieved despite the forming temperature of $T=-20{ }^{\circ} \mathrm{C}$ and despite the promotion of $\alpha^{\prime}$-martensite formation. 


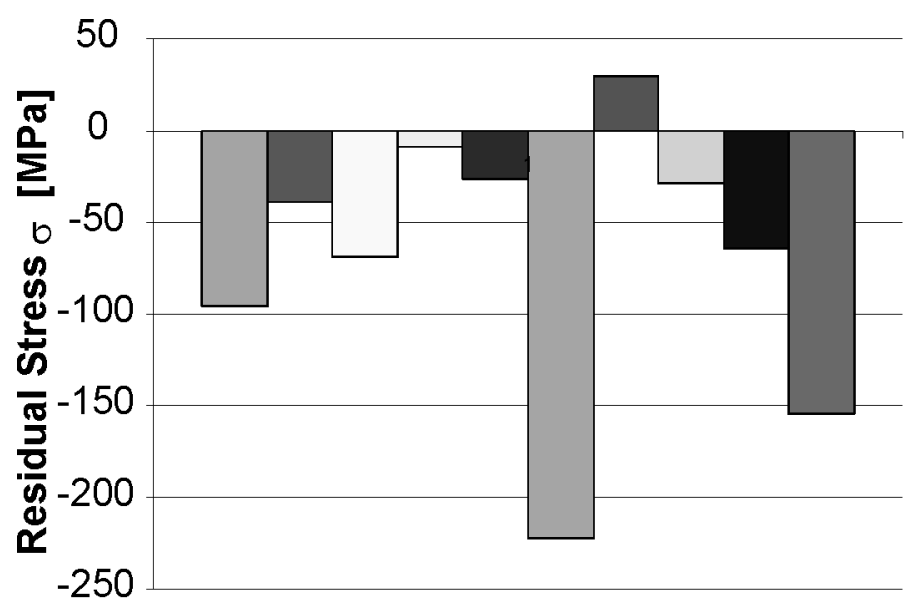

$\square$ TRIP780, $T=80^{\circ} \mathrm{C}$, lateral
$\square$ TRIP780, $T=80^{\circ} \mathrm{C}$, lengthwise
$\square$ TRIP780, $T=-20^{\circ} \mathrm{C}$, lateral
$\square$ TRIP780, T $=-20^{\circ} \mathrm{C}$, lengthwise
$\square$ EN $1.4301, T=20^{\circ} \mathrm{C}$, lateral
$\square$ EN $1.4301, T=20^{\circ} \mathrm{C}$, lateral
$\square$ EN $1.4301, T=-20^{\circ} \mathrm{C}$, lengthwise
$\square$ EN $1.4301, T=-20^{\circ} \mathrm{C}$, lateral
$\square$ EN $1.4301, T=100^{\circ} \mathrm{C}$, lengthwise
$\square$ EN $1.4301, T=100^{\circ} \mathrm{C}$, lateral

Fig. 19: Exemplary presentation of the internal strain measurements for oval multi-radii structures of steels materials TRIP780 and EN 1.4301

In order to build the crash demonstrators in the Double-U-Profile, the profiles were laser welded in Hannover's Laser Zentrum, with a $4 \mathrm{~kW}$ Nd:YAG-Laser, with a feed rate of $3.5 \mathrm{~m} / \mathrm{min}$.

To examine the deformation behavior of this Double-U-Profile, a deformation test-bed was actualized inside the hydraulic press Hydrap. The component is to now be placed in the center of the spherical surface, which is equipped with a load cell, in order to document the force path. The upper part of the test bed is equipped with an even plate which facilitates the actualization of even compressive force. The advantage of this test is that it is possible at any given time during the experiment, to stop the press and to document the deformation behavior in detail. Subsequently, after documentation of the force-path, the experiment can continue.

Connection between the Hardening-Process and the Solidity under Consideration of Temperature Effect. Within the scope of the experiments, new questions arose regarding the complex hardening concept of hardening as a result of forming (work hardening) and phase transformation. Extensive preliminary analyses were carried out in order to quantify the work hardening part and the transformation induced $\alpha$ - martensite formation via differing temperature control systems. The focus lay particularly on the steel materials EN 1.4301 and TRIP780. The selection of these two materials arose from their metastable (and remaining) austenitic structure, although based on the analyses carried out within the scope of CRC project, there is now wide theoretical knowledge regarding the material behavior at room temperature. The hardening concept of the stainless-steel is based on the loading of the alloyed proportions of chrome and nickel. The TRIP780 contrasts the latter with a remaining austenite share of approximately $15 \%$, imbedded within a matrix compiled of ferrite and binate, whereupon the principle of phase conversion lies upon the carbon and manganous alloyed elements. Upon the basis of the correlation between hardness and solidity, micro-hardness measurements were evaluated regarding round structures, at a forming degree of $\varphi=0.12[-]$. The structuring was carried out at differing forming temperatures from $T=-20{ }^{\circ} \mathrm{C}, T=20^{\circ} \mathrm{C}$ as well as $T=100^{\circ} \mathrm{C}$. In regards to the reference and quantification of the work hardening effect, micro-hardening data was examined on the basis of unformed source material. With the aid of this data, the temperature impact on the phase conversion became particularly apparent. Based on this experiment, a qualitative impact of increased hardening, being a result of forming, as well as phase conversion become possible. 


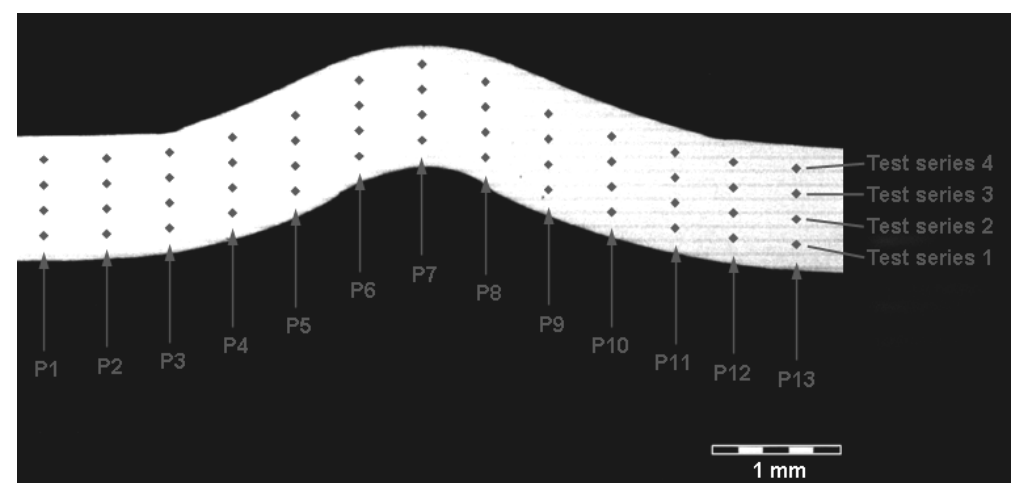

Fig. 20: Sketch of the Principle of measurement of hardness on a polished specimen

As a result of temperature control, the formation of $\alpha^{\prime}-$ martensite is able to be suppressed to a large extent, so that the hardness of kinematic hardening is able to be approximated $[28,27]$. The microhardness measurements follow the grindings of the additionally forming-element's round structures (Fig. 20). Thirteen measuring points were distributed in four different measuring-rows over the sheet-metal thickness and measured, whereby the measuring point P7 presents the center of the vaulting. The distance between the separate measuring rows amounts to $a=0.2 \mathrm{~mm}$.

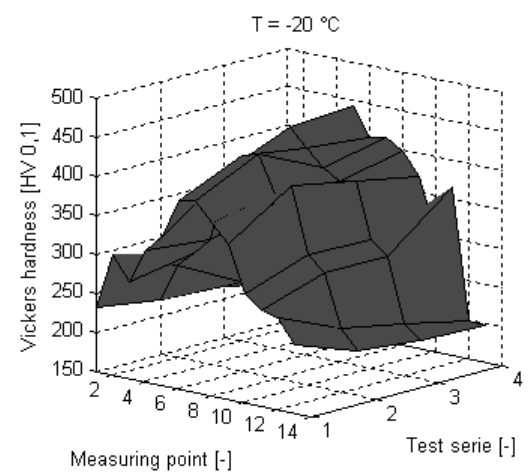

a) $T=-20{ }^{\circ} \mathrm{C}$

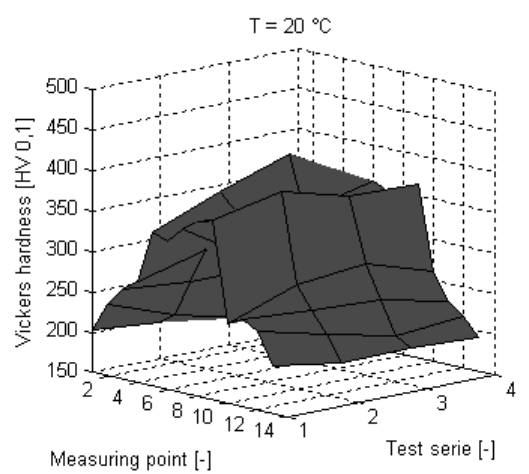

b) $T=20^{\circ} \mathrm{C}$

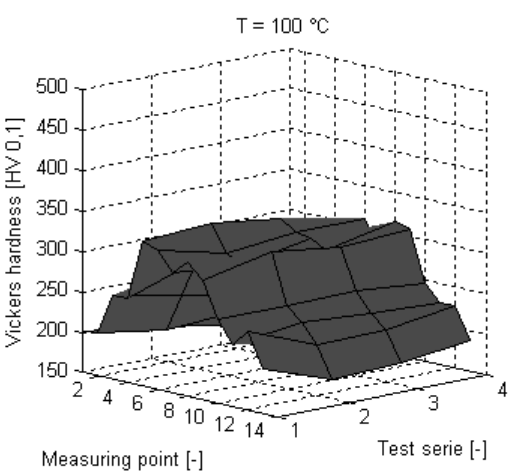

c) $T=100{ }^{\circ} \mathrm{C}$

Fig. 21: Measurements of micro-hardness for the material EN 1.4301 at varying forming temperatures

The analyzed measurements of micro-hardness in the metastable austenite stainless-steel EN 1.4301 on the structure have been produced in Fig. 21 for three different tests as 3D diagrams. Diagram a) presents the hardening-process over the four measuring rows for all measuring points at a forming temperature of $T=-20^{\circ} \mathrm{C}$. In contrast to this, diagram b) exhibits lower hardening values, at a forming temperature of $T=20^{\circ} \mathrm{C}$, which accompanies the low $\alpha$ - martensite content. In Diagram c) a forming temperature of $T=100{ }^{\circ} \mathrm{C}$ was actualized, in order to suppress the $\alpha$-martensite formation, which is reflected in the low hardening rates after Vickers. The highest values were achieved in the measuring rows 3 and 4 .

The solidity can be deduced based on the presented hardening-process. An increase of the solidity, as a result of the promotion of the fencing conversion at low temperatures, but also thru the effect of the forming in contrast to the unformed material, becomes very clear. The micrographs were used in order to document the forming history and, as a consequence, evaluate the martensite formation at a forming temperature of $T=-20^{\circ} \mathrm{C}$ (Fig. 22). It becomes clear that the increase of solidity results accompanies the phase conversion with the forming degree and the degree of strain.

However, an exact separation of the effect of kinematic solidification is not possible by this method. Moreover, it lacks an allocation of the effects of phase conversion as a result of differing strain conditions, as for example the deep-drawing and extension. 
Such experiments were carried out for the remainder of the austenitic steel TRIP780. In Fig. 23, the results of the micro hardening readings after Vickers are presented, in the case of this material, at forming temperatures of $T=-20{ }^{\circ} \mathrm{C}, T=20^{\circ} \mathrm{C}$ and $T=100{ }^{\circ} \mathrm{C}$. Similar to the experiments on EN 1.4301, the emergence of the maximal values are exhibited within the measuring rows 3 and 4 and on the specimen's undersurface. A comparison of these measuring rows shows that the highest hardness values were exacted at room temperature, while at low temperatures of $T=-20^{\circ} \mathrm{C}$, little data developed, which were nevertheless higher than the original value of the unformed material.
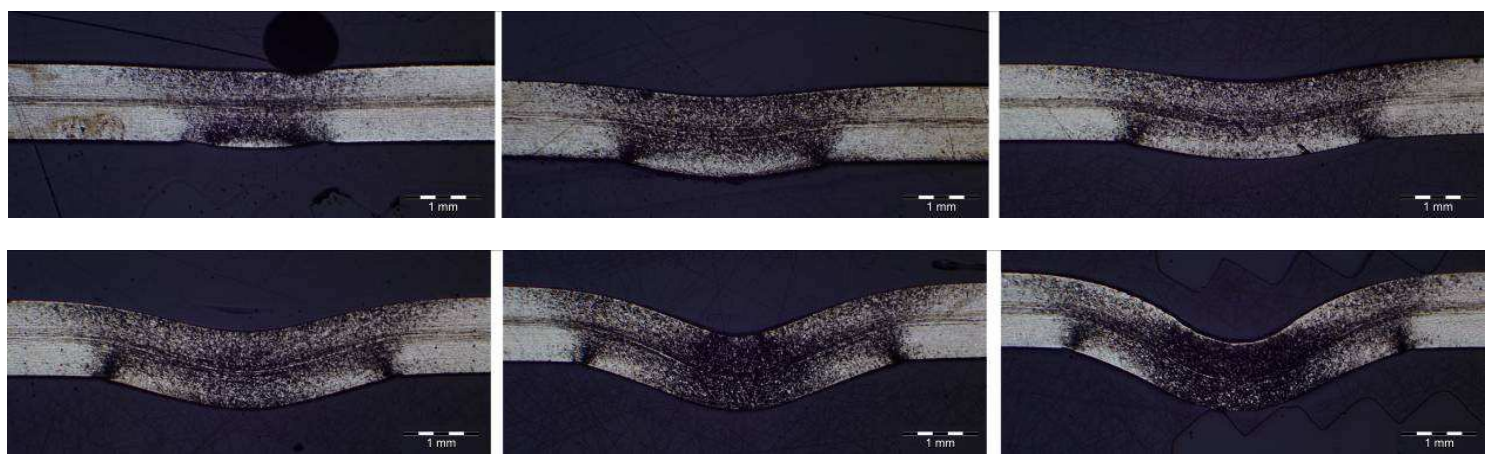

Fig. 22: Deformation History and the $\alpha^{\prime}$-Martensite Formation accompanying it within the Material EN 1.4301, at a Forming Temperature of $T=-20{ }^{\circ} \mathrm{C}$

Based on these results, the different concepts of solidification become distinct once more, within the examined materials. The temperature-dependent solidification concept of the remainder of the austenitic steel in combination with the kinematical solidification is to be examined in detail. [29].

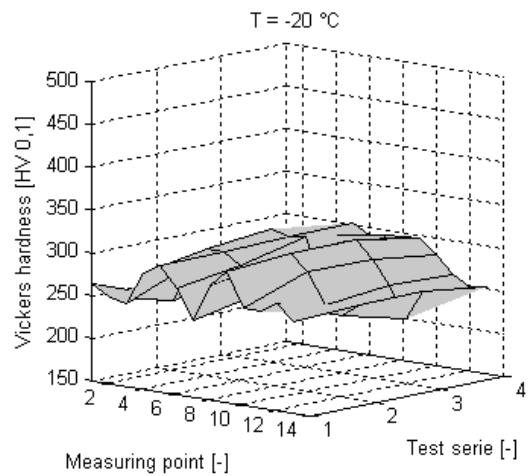

a) $T=-20{ }^{\circ} \mathrm{C}$

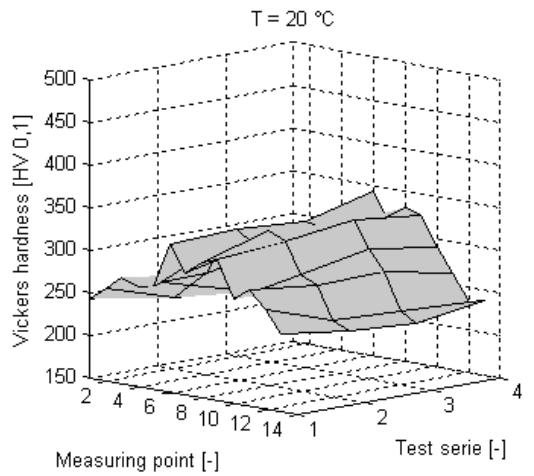

b) $T=20^{\circ} \mathrm{C}$

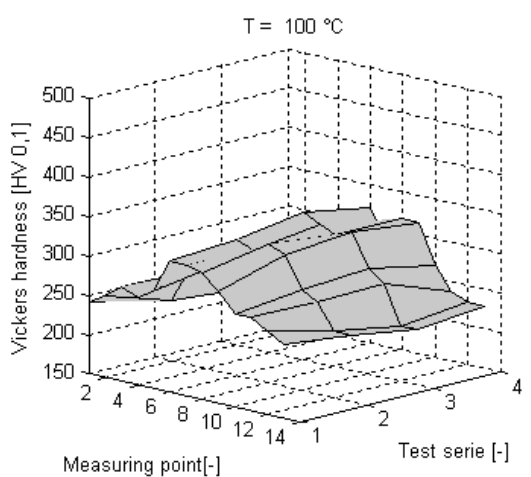

c) $T=100{ }^{\circ} \mathrm{C}$

Fig. 23: Measurements of micro-hardness for the material TRIP780 at different forming temperatures

Impact of the major and minor strain onto the Formation of $\alpha$ '-Martensite. Numerical and experimental studies were carried out in order to examine the impact of the major and minor strain on the formation of $\alpha^{\prime}$-martensite. The data for the Forming Limit curve was analyzed by means of seven geometry tests via the Marciniak-Test. 


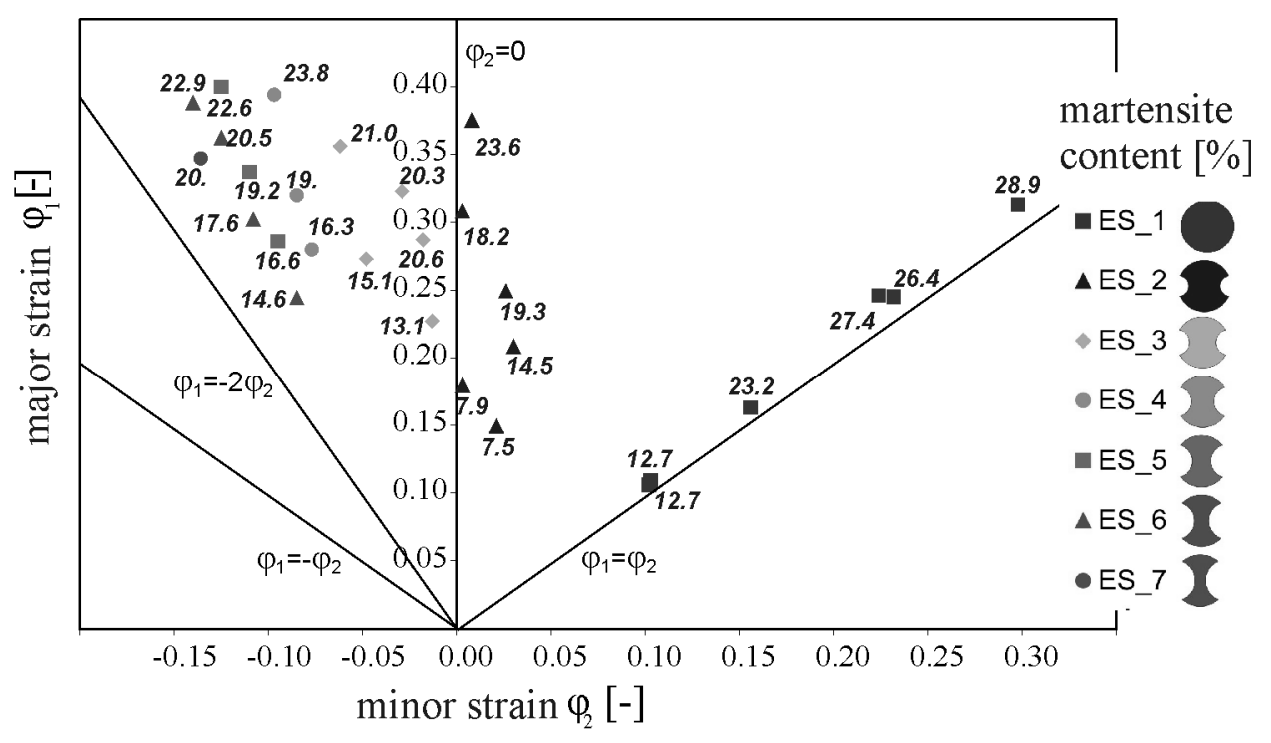

Fig. 24: Martensite Content dependent on major and minor strain [3]

Additionally to the optical analysis via the Autogrid Vario System (Vialux) in order to determine the minor and major strains, tests carried out by the Feritscope MP3C (Fischer GmbH+CoKG) were analyzed to calculate the martensite content.

The data procured was summarized within a diagram, holding information regarding the interrelationship between the minor and major strain and the martensite content (Fig. 24). On the basis of this figure, two tendencies can be determined. The first tendency is that the martensite increases when the major strain increases. The second tendency clarifies that the martensite content increases when the amount of the minor strain increases [3].

Modification of the Material Structure. Within the scope of the numerical projects, the adaptability and extension of an existing material model take place. Its necessary in order to numerically calculate the $\alpha^{\prime}$-martensite formation of EN 1.4301, under quasi-static tensile-strain.

Acting as the starting point of further development is the already existing material model [22], which is based on the model after Tsuta [24] and proves appropriate for the determination of martensite content under the use of shell-elements.

The mathematical equations remaining within the model (particularly Eq 1) take the significance of the influencing factors into consideration, such as temperature $T$, the true strain $\varphi$, the stress condition and the demand of new martensite production, as a result of the shear-tape age within proximity of the first martensite. The necessary material parameters $A-H$ are material dependent and stem from the measurements of the $\alpha^{\prime}$-martensite content and went on to be determined by means of tensile and biaxial tests. This happened as a result of the approximation of the test results using the method of the smallest square of error [8].

It is vital to examine the martensite distribution over the sheet-metal thickness in order to analyze the additional forming-elements in detail.

This can be actualized within an extension of the model onto 3D volume-elements. First follows the adapting of the elastic tensor and predicator, as well as the anisotropy-tensors, onto the flow rule, after Hill, and comparative tension, also after Hill. These were programmed and implemented within the software Abaqus.

Regarding the modelling, consideration of the three main-stress-directions within the sheet-metal area takes place through the use of sign-functions.

$\operatorname{signum}\left(\frac{\sigma_{i}}{\sigma_{j}}\right)$, with $i, j \in\{1,2,3\}$.

The modified equation has the following form: 


$$
\begin{aligned}
\frac{\partial f^{\alpha^{\prime}}}{\partial \varphi}=f\left(T, f \alpha^{\alpha^{\prime}}, \varphi\right)_{\mathrm{Zug}}+E \cdot\left(1+f^{\alpha^{\prime \mathrm{F}}}\right) \cdot \frac{\mathrm{e}^{\mathrm{G}-\mathrm{T}[\mathrm{K}]}}{1+\mathrm{e}^{\mathrm{G}-\mathrm{T}[\mathrm{K}]}} \cdot \\
\quad \sqrt{\varphi} \cdot\left(1+H \cdot \operatorname{signum}\left(\frac{\sigma_{2}}{\sigma_{1}}\right)+H \cdot \operatorname{signum}\left(\frac{\sigma_{3}}{\sigma_{2}}\right)+H \cdot \operatorname{signum}\left(\frac{\sigma_{1}}{\sigma_{3}}\right)\right)
\end{aligned}
$$

However, $f\left(T, f^{\alpha^{\prime}}, \varphi\right)_{\text {Zug }}$ the developed model is meant simply for the single-axle tension condition.

In the case of the upper equation, the material-model is applicable when calculating the martensite content and the triaxial tension state. Particularly the illustration and calculation of the martensite processes over the sheet-metal thickness are made possible.

Fig. 25 exhibits the results of the simulation for one additionally forming element in comparison to the metallographic grinding pattern. Here, a localized forming of an X5CrNi18-10 stainless-steel sheet with the sheet thickness of $s_{0}=1.0 \mathrm{~mm}$ is demonstrated. In this example, the punch has a diameter of $1.8 \mathrm{~mm}$ and a peak radius of $r_{s t}=1.5 \mathrm{~mm}$. The stamping depth is $h=0.1 \mathrm{~mm}$. The section plates are compared thru the forming-zone. On the left, the result of a numerical simulation in Abaqus, with a modified material-model is presented. On the right, the illustration of the grinding pattern is presented with a generated contrasting by means of Beraha 1. A decent correspondence between the courses is qualitatively visible. The areas of the highest martensite concentration are localized in the outer regions. A low martensite concentration is to be found directly within the center of the forming. Already as a result of the comparably low forming, a martensite course is exhibited, which extends far into the sheet-metal thickness. A qualitative comparison proves a great challenge. The measurements, taken by the Feritscope, are mean values over a measuring area of $3 \mathrm{~mm}$ in diameter, and offer no appropriate comparison values for the localized analysis.

By means of a black-white analysis, the amounts of the structure within the grinding pattern are able to be assessed. However, the accuracy, next to the significant influence of the phase-alignment, is effected as a result of the corrosion and the picture quality too. These effects are currently being examined in order to eventually start work on a calibration of the model.
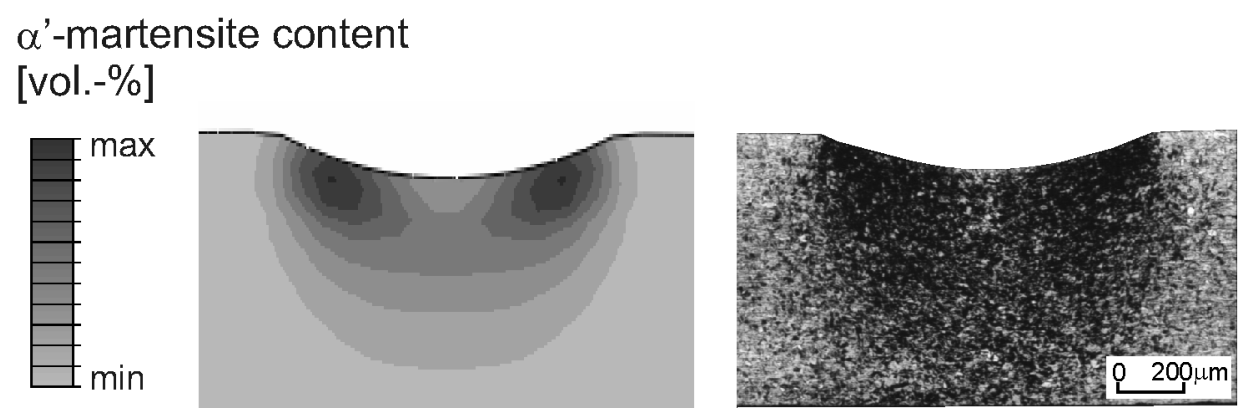

Fig. 25: Grinding pattern of an extended, by means of forming, stainless steel sheet $\left(r_{s t}=1.5 \mathrm{~mm}\right.$, $h=0.1 \mathrm{~mm}$ ) made of X5CrNi18-10 (right) in contrast to the simulation (left)

\section{Martensite in Massive Forming.}

Material Characterization. The material characterization for the massive forming takes place based on upsetting tests with constant strain rate, according to DIN 50 106. In order to complete the flow curve analysis, press force and path measurements of tests with a true strain of $\varphi=1$ were performed. A Software, that was developed at IFUM, enabled an automated assessment of the measurement data. Amongst others, the elastic area of the forming was excluded from the recorded data. Furthermore the noise which had arisen on account of forming was filtered. As a result, the software compiled a flow curve from the mean values of three upsetting tests. In the following 
Fig. 26, the flow curves of the material 1.4301 are presented, dependent on the forming temperature and strain rate.
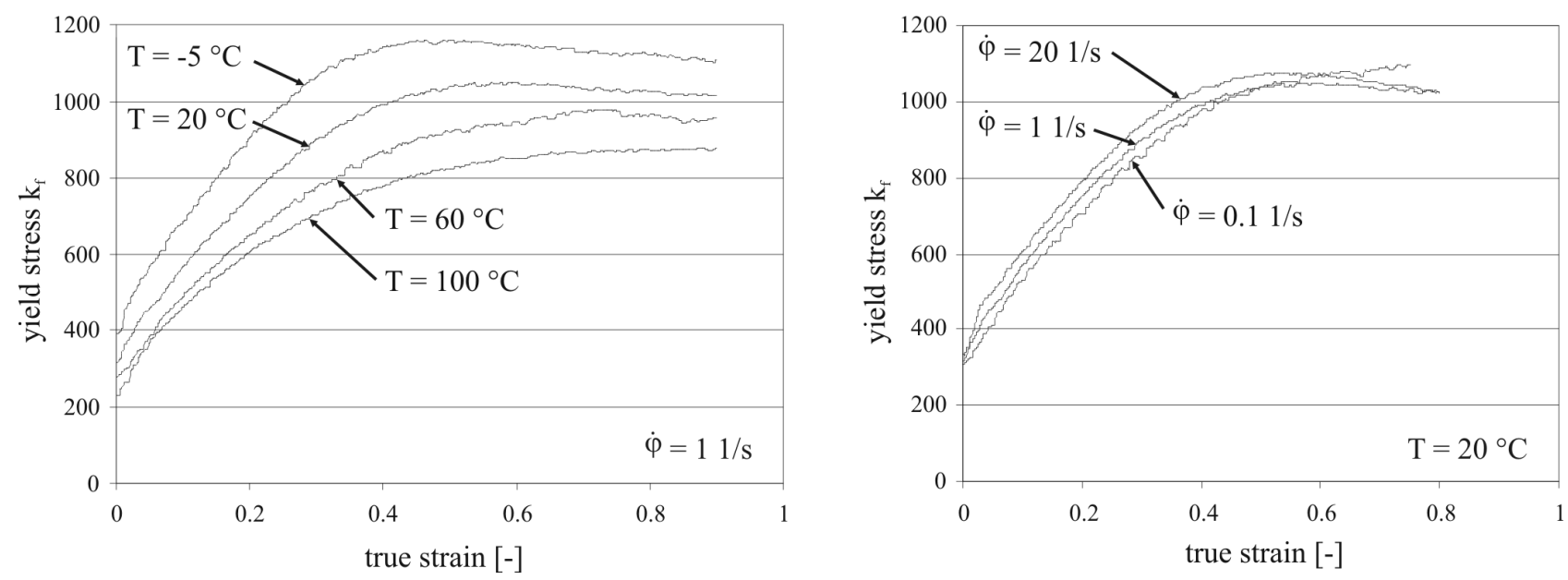

Fig. 26: Flow curves of 1.4301

The yield stress depends on the temperature, strain rate and the material composition. In the case of the above illustrated flow curves of the metastable, austenitic stainless-steel 1.4301, it was not possible to find a correlation between the amount of martensite in the upsetting specimens and the resulting flow curves. The effect of the phase conversion is superimposed by other forming parameters, especially the forming temperature.

Upsetting Tests. A quantitative acquisition of the martensite amount in the specimens of the stepwise upsetting tests took place via the Feritscope of Fa. Fischer. By means of analyzing the specimens, the percental share of the martensite structure, dependent on the forming parameters was analyzed.

The Feritscope is a magnet-inductive hand-held measuring device, composed of a transmitter and a receiver coil. The magnetic-field, generated by the transmitter coil, occurs in interaction with the specimen and is influenced by it. In the receiver coil, a tension develops in proportion to the ferrite content. A concept sketch is illustrated in Fig. 27. By means of recalculating the ferrite content after [22], the martensite content was determined for the material 1.4301. Because of a restricted penetration-depth of the magnetic field into the specimens, a localized measurement of the components was possible using the Feritscope. Based on metallographic analyses, it could be demonstrated that the development of the martensitic structure is locally differentiated than the resolution of the magnetic field reading allows. Therefore, regarding the values that were analyzed with the Feritscope, it is a matter of a mean-value of the ferrite content in the measured testing area. 


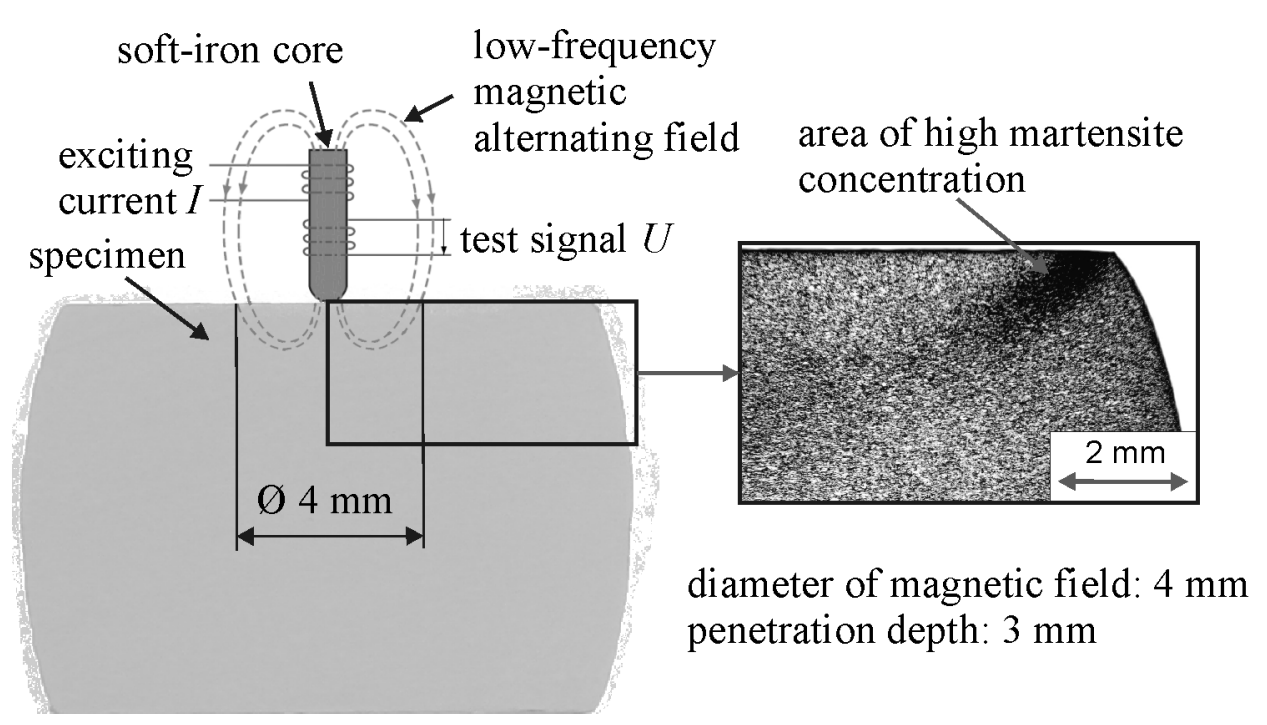

Fig. 27: Illustration of the Fischer Feritscope measuring principle

In order to measure the upsetting tests, the testing probe of the Feritscope was centred upon the end surface. The readings were repeated five times. As described above, all together 91 variations from the different forming parameters were analyzed. The most important results of the experiments are presented in the following.

In Fig. 28, the martensite content in the upsetting tests over the true strain is shown. Already at low forming degrees of $\varphi=0.05$, a slight elevation of the martensite content is detectable. As regards the continued forming, a steady rise is visible.

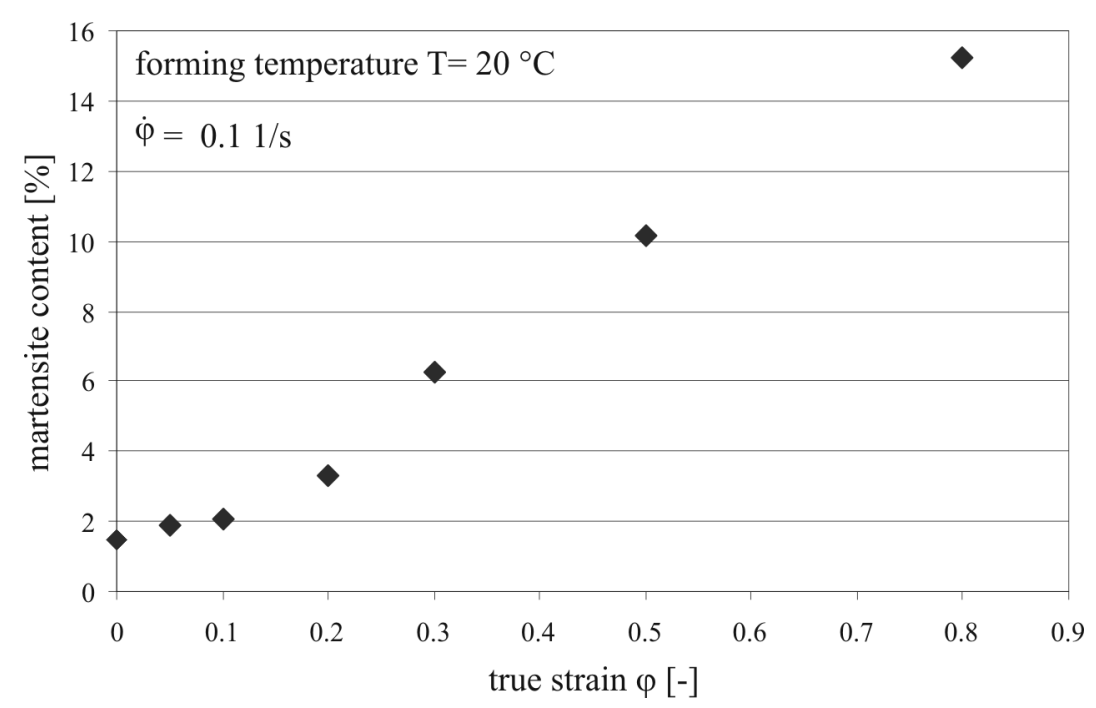

Fig. 28: Relative martensite amount in upsetting specimens, dependent upon the true strain

Based on a row of tests with a constant strain rate of $\dot{\varphi}=0.1 \mathrm{~s}^{-1}$ and differing forming temperatures of $T=-5,20$ and $60^{\circ} \mathrm{C}$, a clear impact of the forming temperature in the martensite content was proven. The temperature dependency of the martensitic phase conversion is presented in Fig. 29. The measuring values for the temperature $T=20^{\circ} \mathrm{C}$ are known from Fig. 28. As a result of the cooling of the specimens at $T=-5^{\circ} \mathrm{C}$, a clear elevation of the martensite content is made possible, as opposed to those experiments taken at room temperature. However, an increased forming temperature reduces the effect of the martensitic phase conversion. At a temperature of $T=60{ }^{\circ} \mathrm{C}$, a phase conversion is close to completely suppressed. 


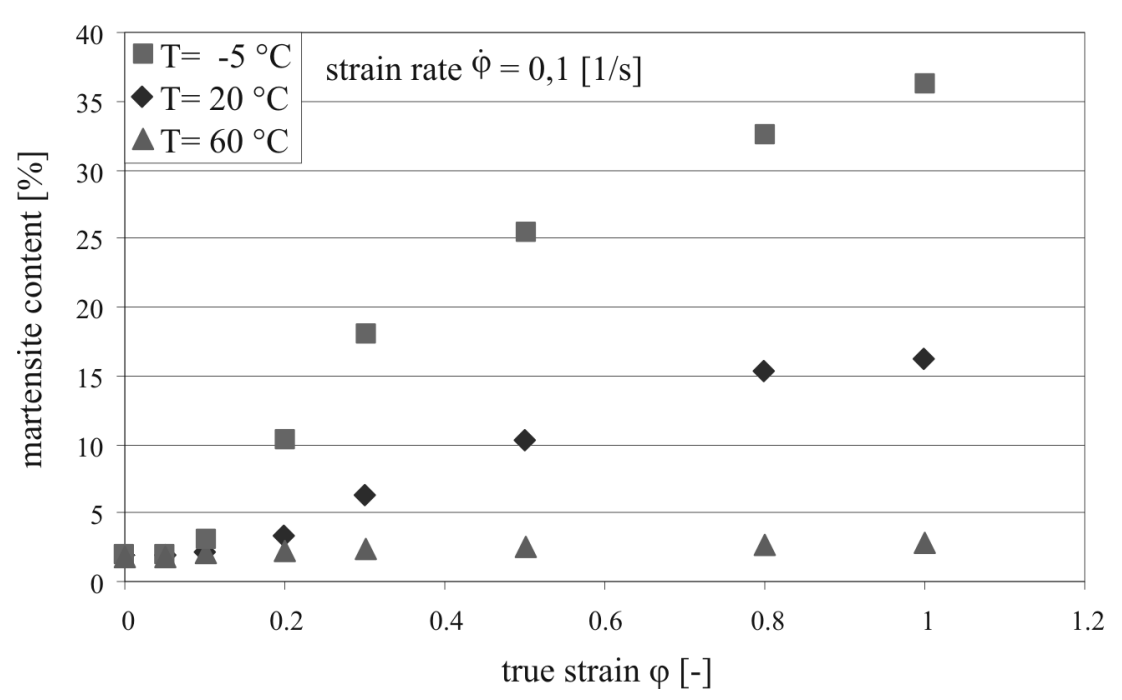

Fig. 29: Relative martensite amount in upsetting specimens at constant strain rate, dependent on the forming temperature and the true strain

Fig. 30, exhibits the dependency of the phase conversion on the strain rate. Three experiment rows were evaluated at a variety of strain rates at room temperature. Within the material 1.4301 an expansion rate dependency takes place, as a result of the phase conversion. From a forming degree of $\varphi=0.2$, a distinct strain rate dependency of the martensite content becomes visible within the specimen. This is the result of an increased adiabatic heating during the upsetting tests at high strain rates. This in turn suppresses the conversion structure at an increased temperature during the forming. Correspondingly, the phase conversion at high strain rates results in lower values.

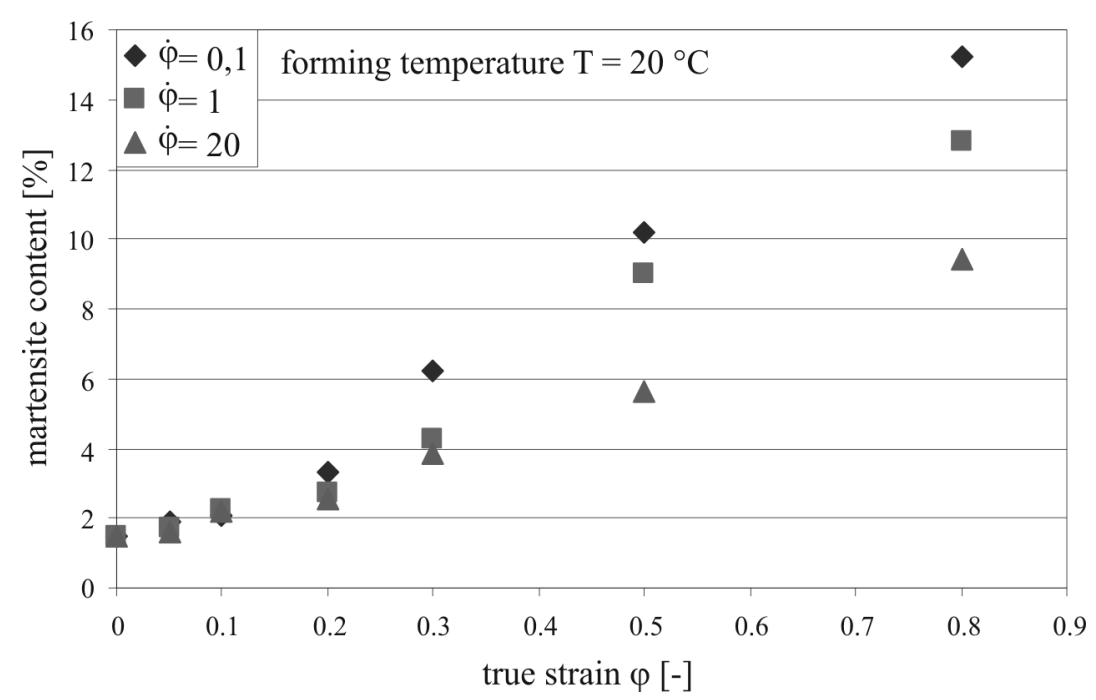

Fig. 30: Relative martensite content within crushing tests at constant forming temperatures dependent on the forming speed and forming degree

The forming degree and the forming temperature are decisive factors within the forming of metastable austenitic stainless steels. Although martensite arises already during low degrees of deformation, the martensitic phase amounts elevates with increasing forming degree within the specimen. As a consequence of the cooling of the specimen, the martensite content can be distinctly increased. For experiments to follow, the temperature range below room temperature is of particular interest. 
Backward cup extrusion (BCE). For the backward cup extrusion (BCE), simulations were carried out with the FE software Forge. The calculation took place, in consideration of the elastic tools, in order to examine the tool strain during cold forming of the material EN 1.4301. At first, a numerical optimization regarding the tool geometries took place in order to reduce the strains that occurred. In Fig. 31, the tool geometry as well as the assumed temperature and strain processes, without temperature regulation of the tools, is exhibited.
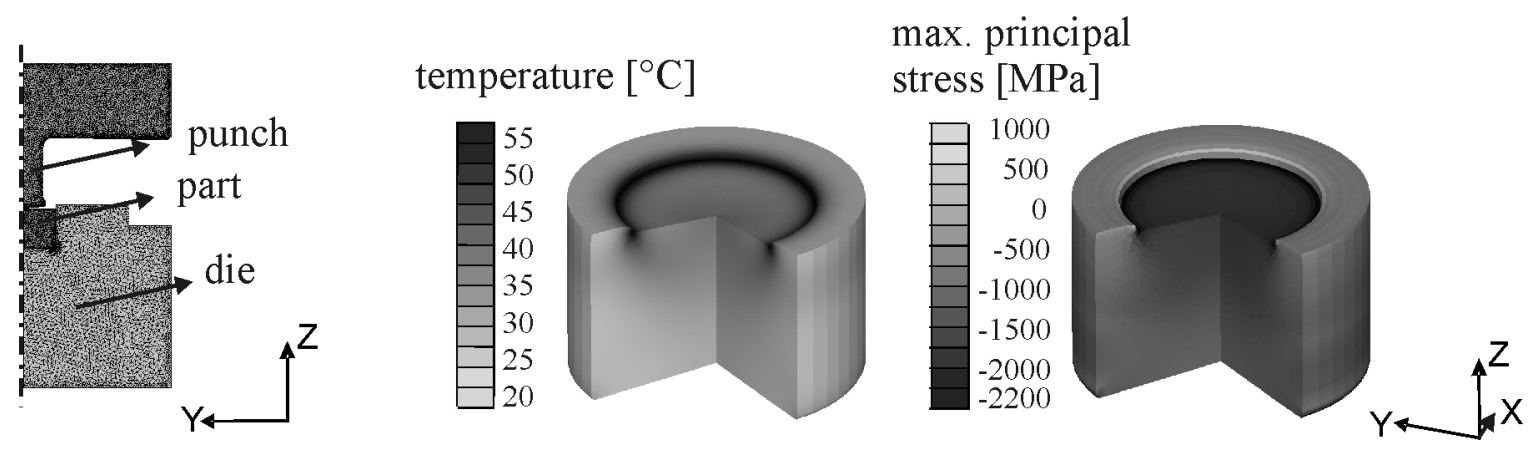

Fig. 31: Simulation results of the BCE: Temperature and maximal principal stress

The goal of the experiments on BCE was to analyse the localized generation of martensite in massive forming components. As opposed to the upsetting tests, the parameter variations could be increased. This was actualized by means of the specimen and tool temperatures that can differ from one another, as opposed to the isothermal upsetting tests. With that, a carefully regulated increase or suppression, respectively of the martensite content is made possible within localized areas. Because the difference regarding the tests with the $2 \mathrm{~mm}$ forming course proves more distinct, the following illustration of results focuses on this series of experiments.

The evaluation of the martensite content took place with the aid of the Fa. Fischer Feritscope after the forming process. The cross section of the cup is presented in Fig. 32. In addition, the measuring points were marked upon which each martensite content test was recorded.

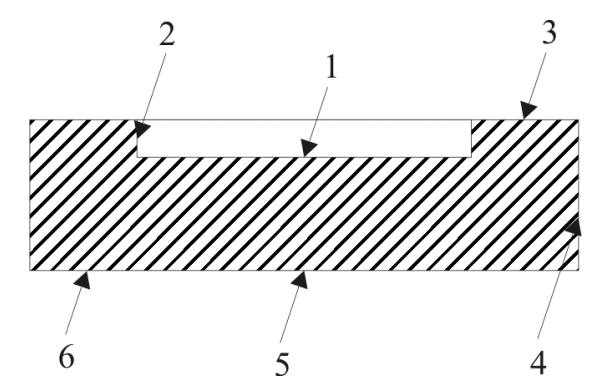

Fig. 32: Measuring points on the BCE specimen

For each measuring point, 5 repetitions were recorded. Apart from both measuring points on the middle axle ( 1 and 5), the position was varied regarding the respective circumference. The martensite content of a specimen, dependent on the measuring position, is exemplarily recorded in Fig. 33. Tools and specimens were tested at a temperature of $T=20^{\circ} \mathrm{C}$. The ram velocity was $v=1 \mathrm{~mm} / \mathrm{s}$.

For the measuring points 3, 4 and 6 the results for all examined test parameters exhibited merely slight differences. This is why in the following, the three remaining measuring points are to be exclusively examined. 


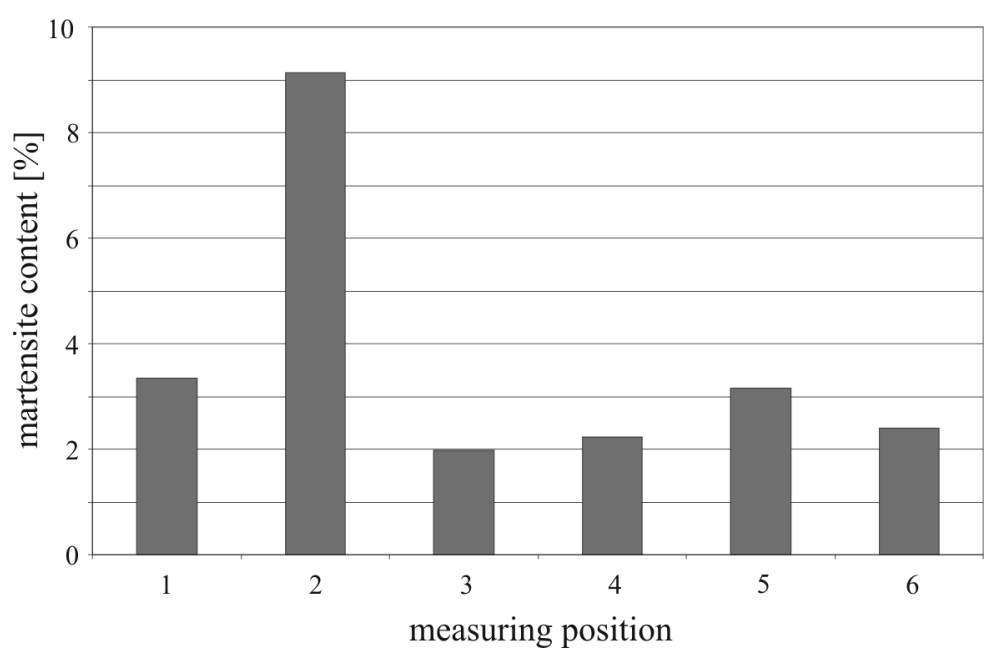

Fig. 33: Martensite content in a BCE specimen

In Fig. 34 the procentual martensite amount is recorded over the rate of forming within two diagrams. In the case of the experiment series presented in the left diagram, the tool and specimen temperatures were identical at $T=20^{\circ} \mathrm{C}$. In the case of the data emitted from the diagram on the right, a sample temperature of $T=-5^{\circ} \mathrm{C}$ and a tool temperature of $T=20^{\circ} \mathrm{C}$ were recorded. Regarding the isothermal experiments (left), the martensite amount within the sample decreases at increased forming rates, as previously observed in the case of the upsetting tests. This takes place as a result of the adiabatic heating. In the diagram on the right, the martensite amount can be increased when a prior cooling of the specimens takes place. The phase conversion increases parallel to increased rate of forming. After the crossing of a maximum, the martensite amount decreases once more at higher rates of forming. This effect took place in the cases of all other experiments, using a variety of tool and specimen temperatures. The reason lies within the temperature differences between tool and specimen. A heat exchange between the tool and the specimen takes place after insertion into the forging die until the end of the forming process. In the case of slow ram velocity of $v=1 \mathrm{~mm} / \mathrm{s}$, the specimen was already warmer at the beginning of the forming process than at a velocity of $v=5 \mathrm{~mm} / \mathrm{s}$. A lower martensite amount is therefore recorded. In the case of a ram velocity of $v=10 \mathrm{~mm} / \mathrm{s}$, the specimen proves at its coolest at the beginning of the forming, although soon enough the effect of adiabatic heating occurs once more and restricts the phase conversion. Furthermore, high martensitic phases share having taken place as a result of cooling the samples from their lower surface.

With these experiments, it could be proven that by introducing localized forming degrees, supplied by the tool geometry, a purposeful adjustment of martensitic phase shares is possible within massiv forming components. By cooling the specimens, the procentual martensite amount can be continually increased.

On the basis of the results described until now, the objective of further experiments has become to purposefully suppress the martensite formation on the lower bases of the specimen (measuring point 5) by means of a tool temperation. In order to achieve this, a heating sleeve was built onto the adapter of the lower tool. A heating of the forging die followed at a temperature of until $T=100{ }^{\circ} \mathrm{C}$. During the heating, the ram was positioned at the highest setting and protected against the heat radiation by an insulation. 


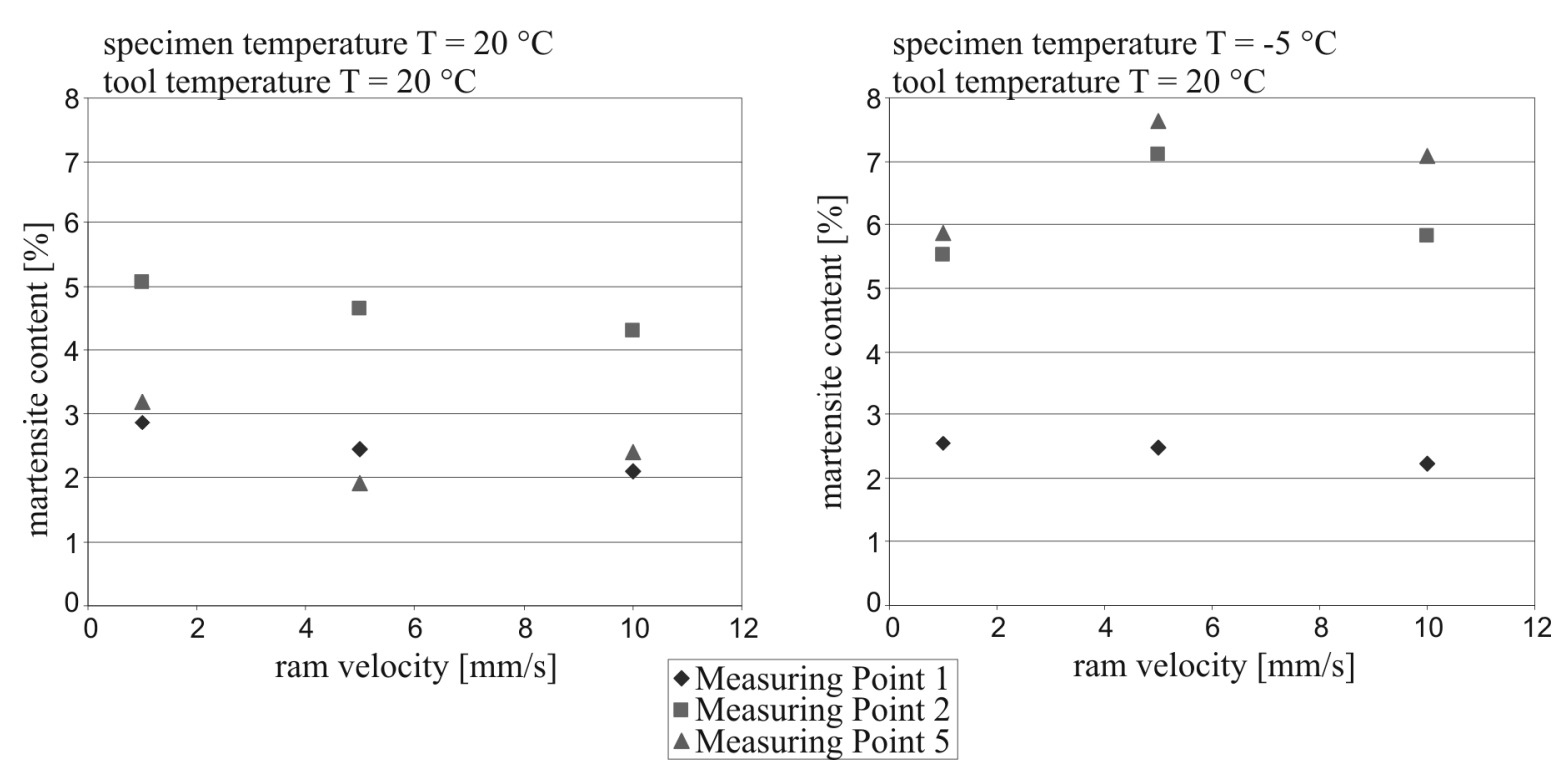

Fig. 34: Martensite content in BCE specimens depending on different forming parameters

In the case of the experiment series at a ram velocity of $v=5 \mathrm{~mm} / \mathrm{s}$ and cooled specimens at a temperature of $T=-5^{\circ} \mathrm{C}$ (Fig. 35, left), the largest amount of martensite can be generated on the upper surface. On measuring point 5, a martensite amount of $12.3 \%$ and on measuring point 2 an amount of $20.3 \%$ martensite was determined. As a result of tool temperature increase and the thereby occuring heating of the specimens, the martensite content is measured at much less, particularly on the contact surfaces of tool and specimen. At a tool temperature of $T=100{ }^{\circ} \mathrm{C}$, the martensite formation upon the base of the specimen (measuring point 5), is close to completely suppressed. The upper surface is warmed by the thermal conduction running throughout the specimens. Based on the low initial temperature of $T=-5^{\circ} \mathrm{C}$, a martensic phase amount of $11.7 \%$ can be reached.

The point of the experiment taking place at $\mathrm{T}=100{ }^{\circ} \mathrm{C}$ is exhibited in Fig. 35 on the right. At high tool temperatures, the rate of forming has a great impact on the martensite amount as a result of the heating of the specimens. At low forming rates the specimen heats up and the martensite evolution is suppressed. At higher velocities the specimens remain colder during the forming, especially in areas that are not in contact with the heated tool. These areas show, in combination with a higher degree of deformation, an increased amount of martensite.

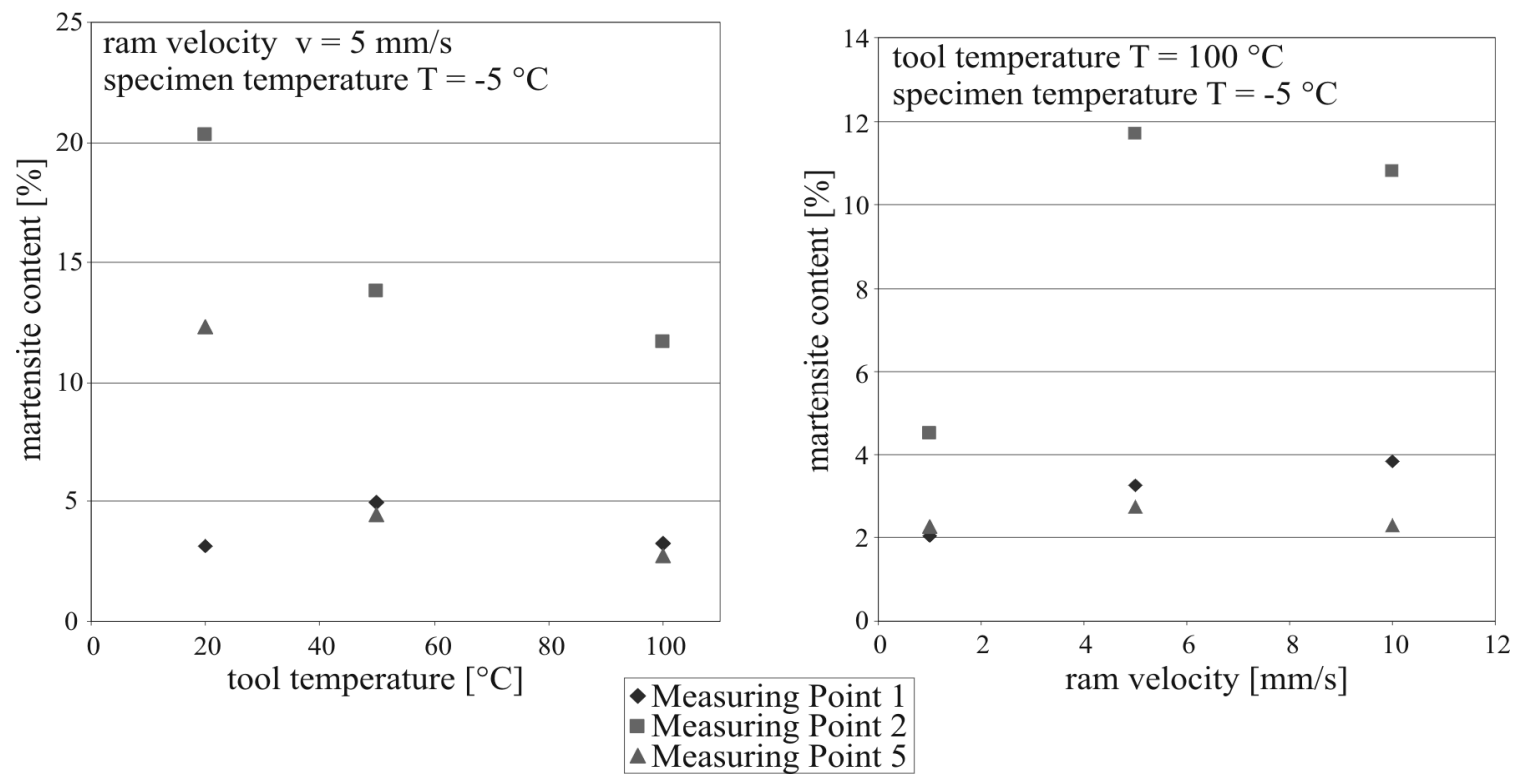

Fig. 35: Martensite content in BCE specimens dependent on the tool temperature 
Based on the $\mathrm{BCE}$, the influence of the forming parameters was analyzed, regarding the procentual martensite amount within a massive forming part. In particularly, the localized phase conversion by a variation of the process parameters was successfully carried out. These insights carry a particular significance for the conversion of future massive forming processes.

More detailed accounts of the experiments presented are to be found in the following publications $[4,6,7,9,10]$.

\section{Summary, Conclusion and Prospects for the Future}

Within the scope of the research activities, partial structural fields within sheet metal components are to be actualized. By introducing structural fields into sheet metal components during the deepdrawing process, the material becomes additionally stretched at these points. As a result, especially strain adjusted components can be produced with locally optimized property profiles, as for example ductile and martensitic high-tensile areas. This division of the component in increasingly drawn out and non-drawn out areas leads to a defined crease within the component as for example in the case of a crash.

In order to examine the structural fields' properties of the structural fields, regarding strength and rigidity, FE simulations as well as experimental analyzes are to be carried out. Additionally, connections between the properties of the structural fields and the components, their grain structure as well as their martensite content shall be examined.

The simulation makes a theoretical extension possible of the current knowledge, regarding the mechanisms that lead to martensite transformation. On the other hand, on account of the extensively researched foundation of knowledge, the process parameters of a localized increase in strength can be carefully selected and optimized. With the aid of numerical calculations, it becomes possible to adjust the component geometry as well as the forming process of the construction to the desired parameter. This helps to enable a well priced and optimized tool set up. The prediction of stress, strain, temperatures and forming degrees are of decisive significance, particularly regarding the adjustment of defined material properties during the forming processes. Moreover, the consideration of the phase transformation of austenite into $\alpha^{\prime}$-martensite is made possible by means of a material model, developed at the IFUM. The model has been made (program-technically) accessible to the software and therefore facilitates the simulation of the martensite content under quasi-static load. Until now, the model has been exclusively applicable for connecting components by means of shell elements.

The knowledge gained from the scope of this project demonstrates a high potential in using the transformation-induced martensite formation as a localized strengthening of the additionally forming elements and effectually forms the foundation for further experiments. Due to the variation of the process parameters -tool temperature for example- the martensite amount can be increased in crossing over to the additionally forming element, whilst the phase conversion in the other areas can be suppressed.

By furthering the research of the mechanisms that lead to martensite formation during the forming process, the material properties, and therefore the component properties, can be controlled at points under particular load, by means of localized adjustment or changing of the grain structure. Therefore, the effect of the martensite transformation is able to be used for highly loaded sheet and solid components, by allowing the necessary material-properties and strengths in particularly loaded areas to be tested in regards to their texture, internal stress and structure, already during the manufacturing process.

Continued basis-oriented experiments are planned, regarding the temperature dependency of the martensite formation and the strengthening increase, connected to this in order to further the focal points of the presented projects. In depth analyzes are to be carried out to facilitate the separation of the strengthening concepts of work hardening and martensite formation. 


\section{Acknowledgements}

We would like to thank the Deutsche Forschungsgemeinschaft DFG (German Research Foundation) for funding this collaborative research centre 675 and Outokumpu Tornio Works Finland for the support with different stainless steels grades.

\section{References}

[1] T. Angel: Formation of Martensite in Austenitic Stainless Steels. Journal of the Iron and Steel Institute, Mai 1954, pp. 165-174, (1954)

[2] A. Bäumer: Verfestigungsverhalten von hochmanganhaltigen Stählen mit TWIP-Effekt, Dissertation, RWTH Aachen, (2009)

[3] E. Doege, B.-A. Behrens: Handbuch Umformtechnik, Springer Verlag Berlin Heidelberg New York, (2006)

[4] B.-A. Behrens, C. Sunderkötter, S. Hübner, J. Knigge, K. Weilandt, K. Voges-Schwieger: Local Strain Hardening of Sheet and Solid Forming Components during Formation of Martensite in Metastable Austenitic Steels. Advanced Materials Research Vol. 22, pp. 5-15, http://www.scientific.net, Trans Tech Publications, Switzerland, (2007)

[5] B.-A. Behrens, K. Voges-Schwieger, S. Hübner: Non-Destructive Testing for the Determination of Transformation-Induced Martensite in Metastable Austenitic Steels. Proceedings of the IDDRG "Forming the Future- Innovations in Sheet Metal Forming", 21.-23. May 2007, Györ, Hungary, pp. 93-100, (2007)

[6] B.-A. Behrens, S. Hübner, K. Voges-Schwieger, K. Weilandt: Local Strain Hardening of Sheet Forming Components during Formation of Martensite in Metastable Austenitic Steels. European Congress on Advanced Materials and Processes (EUROMAT), Nürnberg, (2007)

[7] B.-A. Behrens, S. Hübner, J. Knigge, K. Voges-Schwieger, K. Weilandt: Gezielte Funktionalisierung von Martensit in Blech- und Schmiedebauteilen. 6. Industriekolloquium Clausthal „Hochfeste Strukturen“, 19.-20. Nov. 2007, Clausthal-Zellerfeld, pp. 191-197, (2007)

[8] B.-A. Behrens, K. Weilandt, B. Springub; Verformungsinduzierter alpha'-MartensitAnwendungsgebiete und numerische Abbildung, Festkolloquium Pawelski, Steel Grips, Verlag GRIPS media GmbH, Bad Harzburg, pp.165-177, (2008)

[9] B.-A. Behrens, A. Bouguecha, A. Hundertmark, O. Marthiens, F. Schäfer, K. Voges-Schwieger, K. Weilandt: Aktuelle Forschungsergebnisse am Institut für Umformtechnik und Umformmaschinen. Tagungsbeitrag 19. Umformtechnisches Kolloquium Hannover 2008 „Umformtechnik - ein Wirtschaftszweig mit Potential“, Hrsg: B.-A. Behrens, ISBN 978-3-00-023874-1, pp. 47-70, (2008)

[10]B.-A. Behrens, S. Hübner, J. Knigge, K. Voges-Schwieger, K. Weilandt: Local StrainHardening in Sheet Metal and Forging Components, Steel research int., Volume 2008, No. 3, pp. 165-171, (2008)

[11]B.-A. Behrens, S. Hübner, K. Weilandt, K. Voges-Schwieger.: Local martensitic high-strength structure fields - material properties of metastable austenitic steel. Proceedings of the 6th European Stainless Steel Conference Science and Market, 10.-13. June 2008, Helsinki, Finland, pp. 799-804, (2008)

[12]B.-A. Behrens, S. Hübner, K. Voges-Schwieger: Local martensite evolution in metastable austenitic steels - new material for a changing world. Proceedings of the IDDRG "Best in Class Stamping”, 16.-18. June 2008, Olofström, Schweden, pp. 231-237, (2008) 
[13] S. Hübner, et al.: Bauteile mit lokal spezifischen Eigenschaften sichern Festigkeit bei niedrigem Materialeinsatz, MM Maschinen Markt, Ausgabe 44, ISSN0341-5775, Oktober (2009), pp. 26-29.

[14] S.V. Huck, R. Kawalla: Bedingungen für die Verbesserung der Verformbarkeit hochfester Stähle bei der Blechumformung, Metallurg (2008), Heft 3, pp. 45-48

[15]S. Kranz, J. Ohlert, K. Papamantellos, W. Bleck: Umwandlungsverhalten und mechanischtechnologische Eigenschaften niedrig und hochlegierter TRIP-Stähle. Aachener Stahlkolloquium 1999, pp. 107-115, (1999)

[16]H.-U. Lindenberg, O. Kazmierski, A. Otto: Kaltgewalztes Band aus nichtrostenden Edelstählen und die Anwendungspotentiale. Stahl und Eisen, Heft 5, pp. 37-42, (2000)

[17]N.N.: http://tu-freiberg.de/ze/sfb799/index.html, Offizielle Website des Sonderforschungsbereichs 799 der TU Bergakademie Freiberg, (2009)

[18]E.J. Pavlina, C.J. Van Tyne: Correlation of Yield Strength and Tensile Strength with Hardness for Steels. Journal of Material Engineering and Performance, Vol. 17 (6), pp. 888-893, (2008)

[19]E. Ratte: Sense and Sensitivity of thermo-mechanical forming simulation of metastable austenitic steels. Proceedings of the 6th European Stainless Steel Conference Science and Market, Helsinki, Finland, pp. 787-792, (2008)

[20] W. Schmidt, W. Küppers: Der Einfluß der Austenit-Stabilität auf mechanische Eigenschaften und Umformverhalten von Chrom-Nickel-Stählen. Thyssen Edelstahl, Technische Berichte 12. Band 1986 Heft 1, pp. 80-100, (1986)

[21]M. Smaga,: Experimentelle Untersuchung der Mikrostruktur sowie des Verformungs- und Umwandlungsverhaltens zyklisch beanspruchter metastabiler austenitischer Stähle. Kaiserslautern, Diss., (2008)

[22]B. Springub: Semi-analytische Betrachtung des Tiefziehens rotationssymmetrischer Bauteile unter Berücksichtigung der Martensitevolution, Dissertation, Universität Hannover, (2005)

[23]J. Talonen: Effect of strain-induced $\alpha$ '-martensite transformation on mechanical properties of metastable austenitic stainless steels. Dissertation, Helsinki University of Technology, (2007)

[24]T. Tsuta, R.-J.-A. Cortes: Flow Stress and Phase Transformation Analyses in Austenitic Stainless Steel Under Cold Working. Part 2; JSME Inter-national Journal, Serie A, 36. Band, Heft 1, pp. 63-72, (1993)

[25]K. Voges-Schwieger, B.-A. Behrens, K. Weilandt, S. Hübner.: Transformation-induced martensite evolution in deep drawing processes - a local generation of material properties for load-adapted components. Proceedings of the 14th International Symposium on Plasticity and its Current Applications "Mechanics \& Mechanisms of Finite Plastic Deformation", Kona, Hawaii, USA, NEAT PRESS ISBN: 0-9659463-8-X, pp. 79-81, (2008)

[26]K. Voges-Schwieger, B.-A. Behrens, S. Hübner: Material characterization of local straininduced $\alpha$-martensitic reinforcements. Proceedings of The 12th International ESAFORM Conference on Material Forming, University of Twente, The Netherlands, April pp. 27-29, (2009)

[27]K. Voges-Schwieger, B.-A. Behrens, S. Hübner, S.: Strain-Hardening Part of Strain-induced Martensite Formation, Proceedings of the 15th International Symposium on Plasticity "Macroto Nano-scale Inelastic Behavior of Materials: Plasticity, Fatigue and Fracture", 03.-08.01.2009 in St. Thomas, U.S. Virgin Islands, NEAT PRESS ISBN: 0-9659463-9-8, pp. 139-141. 
[28]K. Voges-Schwieger, B.-A. Behrens, S. Hübner: Enhancing Deep Drawing Processes by Using a Thermomechanical Tool Design, Key Engineering Materials Vols. 410-411 (2009) "Sheet Metal 2009”, pp. 595-600, online at http://www.scientific.net.

[29]K. Voges-Schwieger, B.-A. Behrens, S. Hübner: Material characterization of TRIP780 concerning different forming temperatures and differing local true strains, Proceedings of the 16th International Symposium on Plasticity, 03.-08.01.2010 in St. Kitts, St. Kitts and Nevis (eingereicht am 01.09.2009). 